\title{
Uma Experiência de Desenvolvimento Aberto e Colaborativo (Hackathon) de Ambientes Virtuais de Participação Social na UNIRIO
}

\section{Title: An Open and Collaborative Experience (Hackathon) in the Development of Social Participation Virtual Environments at UNIRIO}

\author{
Jonas da Silva', Renata Mendes de Araujo ${ }^{2,3}$
}

'Programa de Pós-Graduação em Informática -Universidade Federal do Estado do Rio de Janeiro (UNIRIO)

'Faculdade de Computação e Informática - Universidade Presbiteriana Mackenzie (UPM)

'Laboratório de Ludologia, Simulação e Engenharia (LUDES) - Universidade Federal do Rio de Janeiro (UFRJ)

jonas.silva@ufjf.edu.br, renata.araujo@mackenzie.br

Abstract. Social participation in public affairs through ICTs have been widely encouraged around the world. However, the exercise of social participation still needs to evolve in several aspects, both in means, as well as on its effectiveness and on its effects upon public institutions. To explore alternatives for this engagement, this work describes an action research conducted at UNIRIO, aiming to broaden the social participation within the university community with the use of social participation virtual environments (SPVE). The research was comprised an open and collaborative development event - hackathon - aimed at the development of social participation platforms and the promotion of internal participatory practice. This research made possible the understanding of which steps should be developed during a hackathon project in the context of a public university to promote social participation and build SPVE, such as the engagement of members inside and outside the organization, what motivates them, and what were the effects caused by the event at UNIRIO.

Keywords. E-Democracy, Social Participation Virtual Environments, Hackathons, Design Thinking, Action Research, UNIRIO.

Resumo. A participação da sociedade em assuntos públicos por meio de TICs tem sido incentivada largamente em todo o mundo. No entanto, o exercício da participação social ainda precisa evoluir em diversos aspectos, tanto quanto aos meios, quanto em sua efetividade e nos efeitos deste engajamento nas instituições públicas. Com o objetivo de explorar alternativas para ampliar este engajamento, este trabalho descreve uma pesquisa-ação na UNIRIO, visando ampliar a participação da comunidade universitária com o uso de ambientes

Cite as: Silva, J. \& Araujo, R. M. (2018). An Open and Collaborative Experience (Hackathon) in the Development of Social Participation Virtual Environments at UNIRIO (Uma Experiencia de Desenvolvimento Aberto e Colaborativo (Hackathon) de Ambientes Virtuais de Participação Social na UNIRIO). iSys: Revista Brasileira de Sistemas de Informação (Brazilian Journal of Information Systems), 11(4), 117-152. 
virtuais de participação social (AVPS). A pesquisa-ação compreendeu a realização de um evento de desenvolvimento aberto e colaborativo - hackathon - para o desenvolvimento de AVPS institucionais e a promoção da prática participativa interna. Como resultados: a compreensão de quais atividades devem ser desenvolvidas para o projeto de hackathons em uma IFES para promover a participação social e construir AVPS, como ocorre o engajamento dos membros internos e externos à instituição, o que os motiva, e os efeitos do evento na UNIRIO.

Palavras-Chave. Democracia Eletrônica; Ambientes Virtuais de Participação Social; Hackathons; Design Thinking; Pesquisa-ação; UNIRIO.

\section{Introdução}

Acredita-se que a evolução da Administração Pública perpassa pela maior abertura das instituições públicas à sociedade, possibilitando o maior controle e participação social, maior confiança entre os diversos atores da sociedade e as instituições públicas, e maior colaboração para melhor atender as demandas da sociedade (BRAGA \& GOMES, 2016). As iniciativas de participação social por meio de Tecnologias de Informação e Comunicação-TIC (participação eletrônica), de transparência organizacional, de dados abertos, entre outras iniciativas que promovem a abertura das instituições públicas, têm sido incentivadas e apoiadas por organismos internacionais, organizações sociais centradas em questões de governo, grupos de pesquisas, cidadãos e agentes públicos engajados, e diversos outros atores sociais. Ainda, tem sido estabelecido um marco legal, que obriga as instituições a desenvolverem ações que ampliem o controle e a participação social, promovendo a transformação de uma governança "autocentrada" para uma governança digital participativa (MEIRELES, 2015) (JANOWSKI, 2015).

Esse cenário tem sido objeto de estudo de várias investigações de caráter científico, pois diversos desafios decorrem deste novo desenho que se está propondo para as instituições públicas, como a dificuldade em realizar mudanças intra-organizacionais e a falta de efetividade dos instrumentos desenvolvidos para promover a maior abertura e a cooperação entre estas instituições e a sociedade (SUSHA \& GRÖNLUND, 2012) (SÆBØ et al., 2007) (VIEIRA, 2016) (PRZEYBILOVICZ, 2015) (CAETANO et al., 2016) (LEE-GEILLER \& LEE, 2019). No caso do Brasil, apesar de existirem sistemas disponíveis para uso pela sociedade com o propósito de propiciar o diálogo entre o cidadão e as instituições públicas, o exercício da participação social por meio de TIC ainda precisa evoluir em diversos aspectos, tanto do ponto de vista quantitativo e qualitativo dos meios para o exercício desta prática, quanto da efetividade da participação social, do valor público destas práticas percebido pelos cidadãos, dos efeitos que este engajamento cívico gera no governo (CGI.BR, 2014) (CGI.BR, 2016) (FARIA, 2015) (MEIRELES, 2015) (STEIBEL, 2015) (CGI.BR, 2018) (LOPES et al., 2018).

O objetivo geral desta pesquisa é investigar as seguintes questões: como desenvolver sistemas para possibilitar a participação social no âmbito das instituições públicas com a contribuição da sociedade; quais serão as características observadas nos sistemas desenvolvidos por meio desta atuação conjunta; e como se dará a motivação para atuar nestas atividades. Pretende-se, com isso, contribuir para tornar a participação social mais efetiva e intensa. Como objetivo específico, esta pesquisa conduziu uma pesquisaação no âmbito da Universidade Federal do Estado do Rio de Janeiro (UNIRIO), visando 
ampliar a participação social da comunidade universitária com o uso de ambientes virtuais de participação social (AVPS).

A pesquisa-ação foi realizada no contexto de um projeto de pesquisa voltado à inovação institucional e compreendeu a realização de um evento aberto e colaborativo de desenvolvimento (Hackathon) de AVPS institucionais visando a promoção da prática participativa interna na UNIRIO. No projeto de realização do Hackathon, denominado Hack@UNIRIO, o objetivo era aplicar o conhecimento advindo do estado da prática e de pesquisas científicas sobre iniciativas de participação social e Design Thinking. A pesquisa foi de caráter interpretativista, com a finalidade de explorar e descrever a jornada da iniciativa de desenvolvimento aberto e colaboração de AVPS na UNIRIO. Buscou-se, descrever a trajetória do projeto, identificando as atividades realizadas, os fatores que motivaram os indivíduos a atuarem no planejamento e a participar das atividades do Hack@UNIRIO e as características dos AVPS desenvolvidos.

Em relação à UNIRIO, principalmente no âmbito do Centro de Ciências Exatas e Tecnologia (CCET) desta universidade, que foi o principal contexto para o planejamento da pesquisa-ação, as expectativas eram que: a participação social fosse ampliada (facilitada, melhorada); os indivíduos se engajassem mais nas questões relacionadas à universidade; que o espaço universitário fosse mais habitado; enfim, que a cultura institucional em relação à participação social fosse transformada. Eram também expectativas, que fossem concebidos e desenvolvidos, por meio de um Hackathon, protótipos de ambientes virtuais de participação social (AVPS) a serem disponibilizados na UNIRIO. De maneira geral, esses objetivos foram alcançados, foi realizado o primeiro Hackathon da UNIRIO, com a cooperação intensa de vários atores da comunidade universitária e externos a esta, sendo apresentados cinco protótipos de AVPS.

A pesquisa-ação mostrou que: a organização de um Hackathon, de forma aberta e colaborativa, pode ser um instrumento para promover a participação social, assim como a realização do evento, pois ambos promovem o engajamento dos atores imersos no contexto de realização do Hackathon; o desenvolvimento de AVPS por meio de Hackathons se mostrou uma prática capaz de propor estes meios de participação social. Em relação à prática do Design Thinking, que busca trazer os usuários para o cerne do desenvolvimento das soluções que irão servi-los, o modelo de debate de desconferência se apresentou como uma técnica que pode ser utilizada para ampliar o entendimento e empatia dos indivíduos sobre os cenários-problema para os quais as soluções serão propostas, se constituindo como uma atividade imersiva, propiciando a identificação de oportunidades.

A pesquisa-ação é um método de pesquisa em que se busca ampliar o conhecimento científico a partir de uma intervenção ou ação para solucionar um problema que ocorre em uma organização, comunidade ou grupo (FILIPPO, 2011). Um método de investigação coletivo, colaborativo, auto-reflexivo, crítico e realizado pelos participantes da pesquisa são algumas características atribuídas à pesquisa-ação. Ao mesmo tempo que é realizada uma ação em um cenário real, que busca resolver os problemas que foram identificados neste cenário, tenta-se ampliar o conhecimento científico relacionado a esta prática (HERR \& ANDERSON, 2014).

Em uma pesquisa-ação podem ser utilizados abordagens qualitativas e quantitativas para observação e análise de dados. No entanto, o intuito de uma pesquisaação não é prescrever e validar uma solução genérica para um problema, como também 
não é seu objetivo comparar resultados com pesquisas similares. Uma pesquisa-ação envolve os seguintes passos básicos: diagnosticar o cenário de intervenção, planejar a intervenção, executar a intervenção e refletir sobre seus resultados. As principais contribuições de uma pesquisa-ação são a narrativa de todo este processo e implicações observáveis que possam servir de orientação em situações similares.

Seguindo esta abordagem metodológica, o artigo se estrutura da seguinte forma: a Seção 2 apresenta conceitos que compõem o referencial teórico da pesquisa; a Seção 3 descreve os resultados de visitas a contextos reais relacionados à pesquisa, com o intuito de melhor enquadrar o problema a ser investigado; a Seção 4 descreve os objetivos desta pesquisa-ação; as Seções 5, 6, 7 e 8 apresentam, respectivamente, o diagnóstico, o planejamento, a execução e as reflexões sobre a pesquisa-ação; a seção 9 conclui o artigo.

\section{Referencial Teórico}

\subsection{Participação Social e Participação Eletrônica}

A participação social é um direito positivado na Constituição da República Federativa do Brasil' , que estabelece, dentre outras providências: o direito do cidadão de receber dos órgãos públicos informações de seu interesse particular, ou de interesse coletivo ou geral, e o exercício da soberania popular mediante, além do exercício do sufrágio universal, plebiscito, referendo e iniciativa popular. Neste contexto, ações protagonizadas pelo Estado brasileiro, pela sociedade e iniciativas transnacionais, têm contribuído para criar um ambiente favorável à proposição de iniciativas de participação social (PNPS, 2014) (LAI, 2011) (EGTI, 2016) (OGP) (PDA, 2016).

No âmbito desta pesquisa, a participação eletrônica é compreendida como uso das TIC para possibilitar o exercício da participação social. A participação eletrônica consiste no uso das TIC para mediar a interação entre a sociedade e as instâncias governamentais, abrangendo a sua esfera política e administrativa, estando relacionada ao provimento dos meios para possibilitar a participação social nos processos de tomada de decisão e deliberação (SÆBØ et al., 2007) (CURTINOVI, 2015)(MACINTOSH, 2004) (SUSHA \& GRÖNLUND, 2012).

A última pesquisa TIC Governo Eletrônico, que avalia o acesso e uso de TIC no âmbito da administração pública, aponta para a necessidade de ampliação dos meios de participação eletrônica. Nesta pesquisa, em 2017, o percentual de órgãos públicos que ofertam algum mecanismo de participação não chega a 50\% (CGI.BR, 2018) (Figura 1).

\subsection{Ambiente Virtual de Participação Social (AVPS)}

A Política Nacional de Participação Social define AVPS como: [..] mecanismo de interação social que utiliza tecnologias de informação e de comunicação, em especial a internet, para promover o diálogo entre administração pública federal e sociedade civil (PNPS, 2014). AVPS abrangem desde sistemas que possuem poucos recursos de interação entre os cidadãos, até sistemas que possuem diversos mecanismos que possibilitam o debate sobre um tema, a priorização de ideias, a elaboração e a publicação dos produtos gerados, como um projeto de lei, diretrizes de políticas públicas e desenho

\footnotetext{
Constituição da República Federativa do Brasil http://www.planalto.gov.br/ccivil_03/Constituicao/Constituicao.htm 
de serviços públicos digitais. Diversas iniciativas de participação eletrônica com o uso de AVPS estão sendo experimentadas².

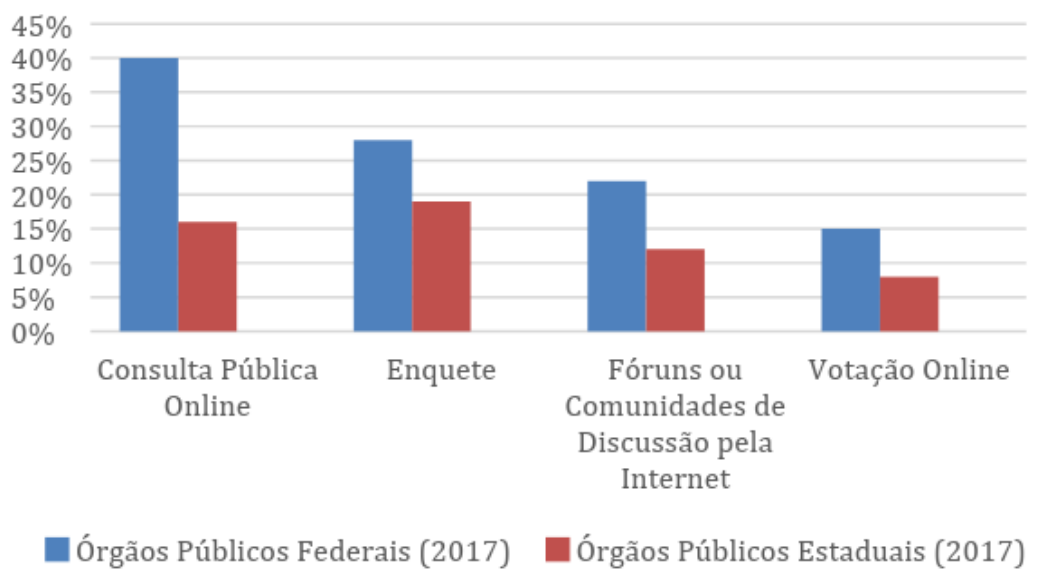

Figura 1 - Proporção de órgãos públicos federais, estaduais e prefeituras, por forma de participação eletrônica. Fonte: (CGI.BR, 2018)

A concepção, desenvolvimento e disponibilização de um AVPS possui desafios. Estes devem ser projetados para um público amplo, onde alguns indivíduos podem ter maior dificuldade no acesso e uso de TIC e não estarem habituados a participar do debate sobre questões de interesse público. O seu uso é voluntário e muitos cidadãos não creem que a participação por meio deste instrumento pode produzir alguma transformação social (FREIRE \& STABILE, 2013) (MAGDALENO \& ARAUJO, 2015) (BARROS \& SAMPAIO, 2017). Visando facilitar o desenvolvimento de AVPS e torná-los mais efetivos, alguns trabalhos têm sido conduzidos com o objetivo de sistematizar o desenvolvimento destes sistemas (SILVA \& ARAUJO, 2015) (ARAUJO \& TAHER, 2014) (PANOPOLOU et al, 2014).

Percebe-se que as iniciativas que visam conceber e desenvolver sistemas com o propósito de possibilitar o exercício da participação social vêm utilizando diversos modelos e processos para construir tais sistemas. Nestas abordagens são empregados tanto arranjos mais fechados, onde o projeto é realizado no âmbito da organização, por equipes designadas para idealizar e desenvolver os sistemas, sendo utilizados processos tradicionais, práticas ágeis, entre outros métodos; como modelos mais abertos e colaborativos, com a cooperação de diversos atores, internos e externos à organização, parceria entre instituições, tanto no financiamento, quando na operacionalização dos projetos, e até a contribuição dos cidadãos.

Para o desenvolvimento do Hackathon desta pesquisa, optamos por não prescrever uma forma de desenvolvimento e/ou especificação dos ambientes, mesmo que baseada em soluções previstas na literatura, pois nos interessava observar como as características destes ambientes emergiriam do processo de colaboração para o design das soluções.

\footnotetext{
${ }^{2}$ Update-Laboratório de Inovação Política na América Latina -https://tendencias.institutoupdate.org.br// 


\subsection{Desenvolvimento Aberto e Colaborativo de Sistemas - Hackathons}

Hackathon é um evento que reúne indivíduos com habilidade e motivação para construir sistemas e outros sujeitos que não têm habilidades técnicas para construí-los, como conhecimento em linguagens de programação, mas querem se engajar nos projetos destes sistemas, podendo cooperar em diversas outras questões inerentes à concepção e ao desenvolvimento de sistemas. Este tipo de evento é de curta duração, dura entre um dia e uma semana, exigindo dos participantes a capacidade de trabalhar intensamente em um curto espaço de tempo e apresentar de forma convincente o resultado do trabalho que foi desenvolvido para os potenciais investidores ou avaliadores. Os propósitos e formatos dos Hackathons são múltiplos. Podem ser centrados em uma determinada tecnologia ou sistema, como, por exemplo, desenvolver novos recursos para um sistema de rede social ou um determinado ecossistema de software. A finalidade do evento pode ser voltada para questões de cunho social ou focadas em um negócio específico, como propor sistemas para ampliar a participação social no processo político (BRISCOE \& MULLIGAN, 2014).

Temos observado que o desenvolvimento aberto e colaborativo de sistemas por meio de Hackathons tem se intensificado tanto promovidos por instituições públicas, como por empresas (BRISCOE \& MULLIGAN, 2014) (FERREIRA, 2017) (SILVA, 2017). Entre os anos de 2012 a 2016, foram identificados 47 Hackathons promovidos pelas instituições públicas brasileiras. Houve um crescimento do número de eventos no ano de 2016, ao qual foram realizados 17 (dezessete) Hackathons, sendo que a maioria dos eventos, 28 (vinte e oito), foram realizados na esfera municipal (FERREIRA, 2017).

Nesta pesquisa, consideramos que Hackathons podem ser vistos como um meio de participação social. Quando realizados por instituições públicas, seus participantes acabam sendo providos de informações sobre estas instituições e/ou, sobre temas de interesse público, e podem se motivar a contribuir. Por outro lado, as soluções propostas podem influenciar as decisões destas instituições a respeito da forma como promoverão a participação (JOHNSON \& ROBINSON, 2014) (EVANS, 2013).

\subsection{Design Thinking}

A abordagem Design Thinking (DT) se refere à utilização ao desenvolvimento de soluções inovadoras, com equipes multidisciplinares, de forma iterativa, colaborativa e empática. Design Thinking coloca as pessoas no cerne do negócio para construir valor com elas e para elas (PINHEIRO et al., 2011), onde o percurso para construção de soluções inovadoras passa pela multidisciplinaridade, colaboração e tangibilização de pensamentos e processos (VIANNA et al., 2012).

No processo de construção do AVPS Dialoga Brasil ${ }^{3}$, o DT foi aplicado com a participação dos cidadãos, conforme foi apresentado no Seminário de Inovação promovido pelo Ministério do Planejamento, Desenvolvimento e Gestão ${ }^{4}$. O DT também

\footnotetext{
${ }^{3}$ Dialoga Brasil. Disponível em <http://dialoga.gov.br/>. Acesso em 07/07/2017.

${ }^{4}$ Participa.br e Dialoga Brasil, inovações e lições aprendidas. Disponível em $<$ http://www.planejamento.gov.br/assuntos/gestao-publica/inovacao/semana-de-inovacao/apresentacoes/l2-12-16h30-renato-simoes.pdf/view>. Acesso em 07/07/2017.
} 
é utilizado como referencial metodológico do evento GovJams no Brasil, que tem o objetivo de propor soluções inovadoras para o setor público.

Desta forma, um dos instrumentos de intervenção desta pesquisa foi introduzir o método descrito por Vianna e seus colaboradores (2012) no processo de realização do Hackathon. O método é composto pelas seguintes fases: Imersão, Análise e Síntese, Ideação e Prototipação.

$\mathrm{Na}$ Imersão, a equipe do projeto se aproxima do contexto do problema, com uma visão holística, tanto dos interessados, patrocinadores e stakeholders, quanto dos atores, empresas, cidadãos, instituições públicas, entre outros, que serão servidos pelas soluções propostas. Na Análise e Síntese, os dados coletados na fase de Imersão são analisados, sintetizados e as oportunidades identificadas a partir do resultado das atividades imersivas são organizadas de maneira a obter padrões e a criar desafios que auxiliam na compreensão do problema. Já na Ideação, o objetivo é gerar ideias, que são soluções propostas para atender aos insights, de forma que a criatividade seja estimulada e sejam geradas soluções alinhadas ao desafio que foi proposto no projeto e aos seus objetivos. A fase Prototipação tem o objetivo de contribuir com a validação das ideias geradas, onde são construídos protótipos, possibilitando que a solução que está sendo projetada seja mais facilmente compreendida por toda a equipe do projeto e pelos usuários.

\section{Visitando cenários de desenvolvimento de AVPS}

No intuito de observar a prática relacionada a projetos de participação eletrônica em cenários reais e identificar similaridades entre eles, foram visitados o Instituto de Tecnologia e Sociedade do Rio (ITS Rio) e o Laboratório de Participação Social da Prefeitura do Rio de Janeiro (LAB.Rio). Estes dois ambientes têm sido referências no Rio de Janeiro de projetos de implantação de plataformas de participação social. Nestas organizações, foram realizadas entrevistas semiestruturadas com gerentes de projetos de desenvolvimento dos ambientes virtuais de participação social Plataforma Brasil e Ágora Rio.

O ITS Rio, organização social que estuda o impacto e o futuro das TICs no Brasil e no mundo, possui em seu portfólio diversos projetos com o objetivo de aumentar o engajamento social para a colaboração na definição de políticas públicas. A visita ao ITS, que ocorreu em outubro do ano de 2015, teve como foco a compreensão das atividades que foram realizadas no desenvolvimento do AVPS Plataforma Brasil, lançado no mesmo ano.

A visita ao LAB.Rio ocorreu em setembro do ano de 2015. Este laboratório de participação, vinculado à Prefeitura do Rio de Janeiro, foi criado em 2014 com o objetivo de experimentar novas formas de participação na gestão municipal da cidade. O objetivo da entrevista era conhecer o processo de concepção do AVPS Desafio Ágora Rio - AVPS por meio do qual o cidadão podia propor e discutir políticas públicas relacionadas a diferentes secretarias e órgãos municipais. Ao final de cada ciclo temático era elaborado um documento com as propostas melhor avaliadas pelos cidadãos, para serem avaliadas

${ }^{5}$ Evento GovJam Brasil. Disponível em <http://igovsp.net/govjam/global-gov-jam/>. Acesso em 07/07/2017. 
pela gestão municipal e, finalmente pelo próprio prefeito, por meio de uma conferência online ao vivo.

A partir das entrevistas sobre o desenvolvimento destes AVPS, algumas características foram identificadas nos projetos: i) Interdisciplinaridade: as equipes que trabalham na concepção e gestão destas iniciativas são compostas por pessoas de diversas áreas de formação, tipicamente estas possuem o chamado "perfil T", ou seja, têm a capacidade utilizar saberes de disciplinas distintas em prol de um objetivo comum, os próprios gerentes de projetos entrevistados tinham formação em Administração e Relações Internacionais; ii) Modelo de desenvolvimento: são utilizados diversos modelos de desenvolvimento para construir os ambientes de participação, tais como: desenvolvimento in-house, onde os programadores integram a equipe que está gerindo o projeto; a adaptação de sistemas destinados a outros fins; e a contratação de empresas especializadas. Não foi identificado nenhum processo de desenvolvimento específico; e iii) Abertura: os projetos são desenvolvidos sob licenças livres, o que permite que as tecnologias que foram implementadas possam ser utilizadas em outras iniciativas e até alteradas, contribuindo para que haja maior colaboração entre os diversos atores. Estes aspectos identificados nas entrevistas foram orientadores na condução da intervenção na UNIRIO.

Este levantamento propiciou também uma mudança na visão dos pesquisadores relacionada à prática de projetos de participação eletrônica. Os pesquisadores tinham uma visão mais tecnicista em relação a estes projetos, em que processos de software poderiam propiciar o desenvolvimento de AVPS mais “engajantes”, mais efetivos. Essa visão foi transformada pelo estado da prática, o enfoque de solução passou a ser voltado para a investigação de quais abordagens poderiam contribuir para propiciar que pessoas com conhecimento em distintas disciplinas pudessem trabalhar de forma colaborativa em projetos de participação eletrônica, como a abordagem Design Thinking e Hackathons.

\section{Objetivos da Pesquisa-Ação}

Conforme mencionado na introdução, os objetivos desta pesquisa-ação foram observar: como desenvolver sistemas para possibilitar a participação social no âmbito das instituições públicas com a contribuição da sociedade (trajetória projetual); quais seriam as características dos sistemas desenvolvidos (características dos AVPS); e como se daria a motivação para atuar nestas atividades (engajamento dos participantes). A intervenção principal desta pesquisa-ação seria a aplicação de metodologias colaborativas e multidisciplinares para o desenvolvimento de AVPS como Hackathons e o Design Thinking. As atividades referentes às etapas do ciclo da pesquisa-ação que foram desenvolvidas nesta investigação são descritas abaixo, e detalhadas nas seções subsequentes.

a) Diagnosticar: nesta etapa foi realizada a caracterização do cenário da pesquisa-ação em relação às questões que se deseja observar, que eram associadas à participação social na UNIRIO, e o uso de sistemas para este propósito. A identificação e análise dos problemas relacionados ao contexto de participação social na UNIRIO foi realizada, de maneira que fosse evidenciada a necessidade de praticar uma ação para ampliar a participação social neste cenário. 
b) Planejar Ação: com base no diagnóstico do cenário da UNIRIO em relação à participação social, foi iniciado o projeto de realização da Hack@UNIRIO, que se baseou em pesquisas científicas sobre projetos de iniciativas de participação eletrônica, no seu estado da prática e na abordagem Design Thinking. Durante o projeto de realização do Hack@UNIRIO os dados foram coletados por meio da observação direta, reuniões, questionário com perguntas abertas, depoimentos individuais, comentários espontâneos e dos dados armazenados nos sistemas (e-mail, Trello, Skype e WhatsApp) utilizados para sustentar a execução do projeto. Já em relação ao engajamento dos participantes do Hack@UNIRIO, os dados foram coletados por meio dos canais digitais de comunicação do evento (site, e-mail, WhatsApp, Facebook), do formulário de inscrição para o evento, observação direta, entrevistas com perguntas abertas, depoimentos individuais, comentários espontâneos e questionário com perguntas abertas. A gravação audiovisual das atividades realizadas no evento também foi utilizada como fonte de coleta de dados.

c) Intervir: a intervenção (ação) proposta nesta pesquisa-ação foi a condução do projeto de realização do Hack@UNIRIO, cujo objetivo era o desenvolvimento de AVPS, a partir da cooperação da comunidade universitária. O escopo deste projeto abrangia a organização e realização do Hackathon.

d) Avaliar e Refletir: os resultados advindos da execução do projeto de realização do Hack@UNIRIO foram avaliados e realizada a reflexão sobre os seguintes aspectos: a aprendizagem que esta jornada proporcionou em relação a como fazer um Hackathon aberto e colaborativo (trajetória projetual); os aspectos motivacionais que puderam ser observados em relação aos indivíduos que atuaram na organização do evento e dos que participaram das suas atividades (engajamento da equipe e dos participantes); as características dos AVPS desenvolvidos durante o evento; e os efeitos percebidos nos indivíduos e na UNIRIO após a realização deste evento.

\section{Diagnóstico do Cenário de Intervenção}

A Universidade Federal do Estado do Rio de Janeiro (UNIRIO), é uma Instituição Federal de Ensino Superior (IFES), fundada em 1979, reconhecida pela diversidade de seus cursos. Esta universidade tem atuação em áreas do conhecimento mais tradicionais, como Direito e Medicina, que estão presentes na maioria das universidades brasileiras, e em áreas que possuem poucos cursos de graduação e pós-graduação, como Biblioteconomia, Teatro e Música, sendo uma das referências nacionais nestas áreas do conhecimento.

O ambiente da pesquisa-ação foi o Centro de Ciências Exatas e Tecnologia (CCET), onde a necessidade de evoluir a participação social foi percebida, embora a intervenção realizada também tenha implicações para outras unidades da UNIRIO, bem como para membros externos.

\subsection{Participação Social e Eletrônica na UNIRIO}

Nas IFES, em geral, os instrumentos utilizados para possibilitar que a comunidade universitária exerça uma participação mais ativa, apresentando suas demandas e propostas para resolver questões que lhe afetam, bem como participar da deliberação e do ciclo de políticas institucionais, são: as eleições diretas para alguns cargos, as assembleias, as consultas públicas sobre algumas questões, os conselhos e os colegiados, aos quais são indicados representantes de diversos setores e classes funcionais da instituição. Na UNIRIO, os instrumentos de participação são similares aos que foram 
descritos, predominando as formas mais tradicionais para o exercício da participação da comunidade universitária, com reuniões presenciais, consultas públicas online não interativas, não sendo expressivo o uso das TIC nestes processos, principalmente no estímulo à participação da comunidade.

Conforme a última autoavaliação realizada na UNIRIO no ano de 2016, a instituição possui fragilidades e potencialidades que estão relacionadas a várias questões. Indicadores relacionados a Políticas de Atendimento aos Estudantes foram considerados potencialidades da universidade, enquanto que suas fragilidades residem na adequação da infraestrutura, programas de qualificação e capacitação profissional, responsabilidade social e acesso à documentação formal.

Dentre as ações propostas no relatório de autoavaliação da UNIRIO, destaca-se: incentivar, fortalecer e ampliar iniciativas que visem o compartilhamento de experiências, ferramentas, tecnologias e base de dados entre a Diretoria de Tecnologia da Informação e Comunicação (DTIC), a Coordenadoria de Comunicação Social (Comso) e a PróReitoria de Graduação (PROGRAD). Neste cenário, é destacada a necessidade de que a Administração Superior fomente projetos nos quais se possam desenvolver alternativas para aperfeiçoar os sistemas de comunicação entre as diferentes esferas administrativas da universidade e os membros da comunidade docente, técnico-administrativa e discente.

O envolvimento da comunidade universitária no referido processo de avaliação é uma questão destacada no relatório, neste, o índice de respondentes foi de 5,93\% (1.145 participantes). É argumentado que na UNIRIO é necessário haver uma sensibilização da comunidade universitária para que a haja uma participação significativa. O diálogo com a comunidade universitária, considerada uma instituição complexa, também é destacado como um dificultador, em função da sua heterogeneidade.

\subsection{Experiência de Desenvolvimento de um AVPS na UNIRIO}

O AVPS Ouvidoria Social foi desenvolvido na UNIRIO no contexto de disciplina de pósgraduação, com a finalidade de permitir à comunidade do CCET relatar problemas (reclamações), compartilhar visões, sugerir soluções sobre assuntos relacionados à instituição e apoiar ou criticar estas reclamações. A especificação do AVPS Ouvidoria Social foi baseada nas características de outros AVPS com propósitos similares e em sistemas de redes sociais, sendo incluídos alguns elementos de jogos, como contagem de pontos por atividades realizadas no ambiente, níveis, progresso, desafios, badges e ranking (CLASSE et al., 2016).

O estudo exploratório qualitativo do uso do Ouvidoria Social em uma disciplina de curso de graduação, demonstrou que o que mais motivou o uso do AVPS, conforme o questionário respondido pelos alunos, foi a possibilidade de contribuir para realizar melhorias na UNIRIO e a possibilidade de ganhar ponto extra na disciplina (motivação extrínseca). No entanto, dentre as informações coletadas, foi registrado o desejo de institucionalização do AVPS na universidade e que os alunos pudessem participar deste projeto. 


\section{Planejamento da Ação: O projeto Ampliando a Participação Social na UNIRIO e o Hack@UNIRIO}

Por iniciativa da Pró-Reitoria de Pós-Graduação e Pesquisa (PROPG) da UNIRIO, no ano de 2016 foi publicado o Programa INOVA UNIRIO, cujo objetivo geral era apoiar projetos de pesquisa, novos ou em andamento, onde o objeto fosse a UNIRIO, a serem desenvolvidos por docentes no âmbito da universidade, fomentando a inovação institucional. A partir da publicação deste edital, o projeto de pesquisa Ampliando a Participação Social na UNIRIO foi elaborado com base no diagnóstico sobre participação social na UNIRIO.

O propósito do projeto foi realizar uma ação no ambiente da UNIRIO, no intuito de melhorar os seus processos, a participação da comunidade universitária e a integração da universidade com a sociedade, posicionando a instituição como uma universidade participativa, transparente e orientada aos objetivos sociais. O projeto de pesquisa previa o desenvolvimento de soluções inovadoras para promoção da participação eletrônica na universidade, em consonância com as diretrizes governamentais, com vistas à melhoria e transparência dos processos internos, à ampliação da integração, melhoria da convivência e da vida universitária, e à ampliação da educação para a cidadania, missão primordial das instituições públicas federais de ensino superior.

Algumas características inerentes à construção dos AVPS via Hackathons foram elencadas no projeto, tais como: o uso de metodologias colaborativas e multidisciplinares de desenvolvimento, e a participação da comunidade universitária, com alunos de várias áreas, compondo a visão sociotécnica necessária para o desenvolvimento efetivo destes sistemas. Os cenários-problema para proposição de soluções de AVPS seriam identificados no contexto da instituição, iniciando pelo CCET, podendo ser incluídos outros contextos da UNIRIO.

A organização do Hack@UNIRIO demandou a cooperação de diversos atores da UNIRIO, entre professores, técnico-administrativos em educação e alunos, instâncias administrativas e gestoras da universidade. Esse esforço conjunto para realizar o Hackathon, que oportunizou que os diversos saberes dos integrantes da sua comissão organizadora fossem explicitados e ocorresse uma aprendizagem cooperativa, propiciou a interação entre diversos atores da universidade.

\subsection{Inicialização do Projeto}

A equipe nomeada no projeto Ampliando a Participação Social na UNIRIO iniciou as discussões sobre o Hack@UNIRIO no mês de setembro de 2016, sendo composta por integrantes do Grupo de Pesquisas e Inovação em Ciberdemocracia (CIBERDEM) e pelo professor coordenador do Semantics \& Learning (SaL). Posteriormente, um aluno do Bacharelado em Sistemas de Informação (BSI) da UNIRIO passou a integrar o projeto, este aluno era bolsista de iniciação científica da universidade, pesquisador do CIBERDEM e associado ao projeto. Visando captar novos integrantes para $\mathrm{o}$ desenvolvimento das atividades do projeto, principalmente em relação à organização do Hackathon, o projeto foi apresentado para a comunidade universitária da UNIRIO.

Inicialmente foram contatados os possíveis interessados vinculados ao CCET, onde a equipe tinha maior alcance, que foram: os professores do Departamento de Informática Aplicada (DIA), os representantes dos discentes do BSI e do Programa de 
Pós-Graduação em Informática (PPGI), a Decania, o Núcleo de Tecnologia da Informação (NTI) e os representantes das empresas juniores vinculadas ao BSI - Uniriotec Consultoria - e ao curso de Bacharelado em Engenharia de Produção da UNIRIO - Athena Consultoria. Todos os representantes destes atores se engajaram no projeto e passaram a cooperar para a realização de diversas tarefas referentes à organização do Hack@UNIRIO. Alguns alunos integrantes do grupo de pesquisas SaL, que já estavam habituados a participar de Hackathons, alunos do BSI e do PPGI também se engajaram no projeto, assim como os alunos dos cursos de graduação da UNIRIO inscritos na disciplina de Atividades Complementares de Extensão (ACE).

O projeto também foi apresentado para a Diretoria de Tecnologia da Informação e Comunicação (DTIC) da UNIRIO, que era vista como uma parceira estratégica para a realização do Hackathon, pelo seu know-how em relação aos processos organizacionais da universidade, desenvolvimento tecnológico e implantação de TIC nesta instituição. Desta forma, o apoio da DTIC, além de contribuir para a organização do Hackathon, poderia facilitar a implantação e sustentação dos AVPS propostos no Hackathon. A DTIC também se tornou parceira do projeto, se comprometendo em relação à implantação das soluções propostas durante o Hackathon, e alguns membros desta diretoria passaram a integrar a equipe de organização do evento.

O projeto Ampliando a Participação Social na UNIRIO se apresentava como uma oportunidade para os integrantes da comunidade universitária alcançarem diversos objetivos. Alguns objetivos eram de caráter pessoal (motivação intrínseca), vários sujeitos gostavam de participar de maratonas hackers, seja no desenvolvimento de soluções ou na organização destes eventos; e alguns indivíduos tinham ambições profissionais, pois também havia espaço para desenvolver ou acelerar projetos pessoais, de pesquisa e institucionais (motivação extrínseca).

\subsection{Prática de Hackathons}

A equipe que foi constituída no início do projeto não tinha experiência na vivência de Hackathon. No intuito de ampliar o conhecimento sobre a prática de Hackathons, buscando informações sobre o seu planejamento, realização e público, foi realizada uma visita ao Hackathon em Saúde, que ocorreu na Fundação Oswaldo Cruz (Fiocruz) nos dias 26 e 27 de novembro de 2016. Este Hackathon tinha como objetivo, conforme o seu regulamento, desenvolver aplicativos e inovações tecnológicas para o Sistema Único de Saúde (SUS), podendo ser sistemas para dispositivos móveis (aplicativos) ou jogos digitais voltados para os temas que foram propostos.

A visita ao evento da Fiocruz possibilitou ao pesquisador vivenciar a prática deste tipo de evento. Em conversa com o instrutor da visita, que também participou da organização do Hackathon em Saúde, as seguintes questões foram apresentadas: os Hackathons têm um índice de não comparecimento em torno de $30 \%$, o espaço que será utilizado pelas equipes precisa ser preparado para isso, os patrocinadores foram empresas que já possuíam algum relacionamento com a instituições pública organizadora, houve dificuldade para conseguir patrocínio de alimentação (o motivo alegado foi a crise brasileira), a maioria dos participantes eram estudantes universitários e o que mais os motivou foram os desafios propostos e o jantar com pizzas.

Outros Hackathons realizados por instituições públicas também foram analisados: o Hackathon ANS e APP Challenge, ambos foram promovidos por instituições públicas, 
a Agência Nacional de Saúde e a Universidade Federal do Rio Grande do Sul (UFRGS), contribuindo para coletar informações sobre os instrumentos que instituições públicas podem utilizar para promover este tipo de evento, como o formato de edital, os patrocinadores e apoiadores, o público alvo e premiações.

\subsection{Processo para Condução do Projeto}

Embora vários Hackathons estejam sendo realizados, o conhecimento sobre como conduzir tais projetos não tem sido muito disseminado no Brasil, o aprendizado fica mais restrito às pessoas que os idealizam, o conhecimento é tácito. À época do início desta pesquisa-ação, não havia sido identificado nenhum processo sistematizado, que pudesse ser utilizado como referência para realizar um projeto de um Hackathon em uma universidade pública.

Dada a ausência de um processo explicitamente definido para a condução de Hackathons, e considerando o cenário da participação social na UNIRIO e os objetivos específicos desta pesquisa-ação, foi proposto um processo para conduzir o projeto de realização do Hack@UNIRIO.

O objetivo não foi elaborar um processo detalhado, com a definição e descrição de todas as atividades necessárias para realizar um Hackathon, com as suas entradas e saídas, artefatos e guias de referência, e aplicá-lo para conduzir o projeto para realizar um Hackathon, ou seja, um processo prescritivo. Buscou-se aprender com a prática, evoluindo o processo à medida que este era aplicado no cenário real, no intuito de que este fosse retroalimentado com a cooperação dos indivíduos que se engajaram no projeto e pelos resultados obtidos com a aplicação das atividades propostas em cada etapa, sendo um aprendizado coletivo.

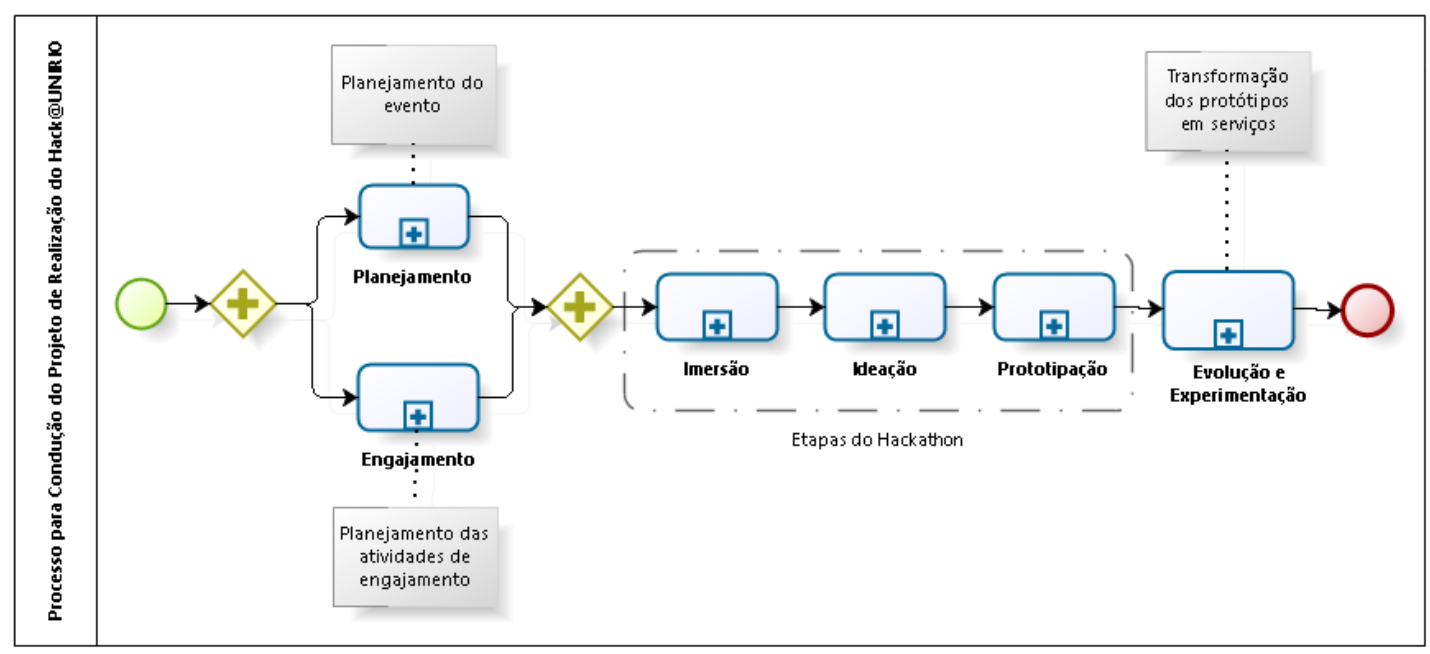

Figura 2 - Processo para Condução do Projeto de Realização do Hack@UNIRIO (SILVA, 2017)

As seguintes etapas foram elencadas inicialmente para o processo (Figura 2): i) Planejamento: definir, planejar e executar as atividades necessárias para realizar o Hackathon, de acordo com as características que se deseja para o evento; ii) Engajamento: pode ocorrer juntamente com as atividades de planejamento, onde são definidas, planejadas e executadas as atividades com o objetivo de despertar o interesse, motivar, engajar a comunidade universitária a participar do Hackathon; iii) Imersão: 
ampliar o conhecimento dos participantes do evento sobre os seus objetivos, o seu tema e os cenários-problema relacionados, de forma que fossem extraídas informações que contribuíssem para gerar insights, que consiste na identificação de oportunidades a partir destas informações; iv) Ideação: os participantes do evento podem propor soluções tecnológicas a partir do conhecimento advindo das atividades imersivas, do conhecimento que foi explicado, dos insights que foram gerados; v) Prototipação: incentivar a construção de protótipos tecnológicos para tangibilizar as soluções que foram propostas; vi) Evolução e Experimentação: em geral, os Hackathons não têm a intenção de viabilizar a disponibilização instantânea das soluções apresentadas, o objetivo é desenvolver protótipos funcionais com a finalidade de explicitar as ideias, e futuramente transformá-los ou incorporá-los a serviços digitais já existentes, que seria o objetivo desta etapa.

\subsection{Gerenciamento do Projeto}

Após discussões iniciais, o Plano de Projeto do Hack@UNIRIO foi elaborado usando a metodologia Project Model Canvas (PMC) (FINOCCHIO JUNIOR, 2013). Destacamos alguns de seus aspectos mais relevantes nesta seção.

Escopo: entendeu-se que a evolução da participação social na UNIRIO perpassa por melhorar a convivência na universidade, que está associada a diversas questões: como ter espaços que possibilitem a evolução das relações interpessoais, de forma que a comunidade habite mais a universidade e, consequentemente, se interesse mais pelo que está acontecendo neste ecossistema, usufruindo de todos os benefícios que este pode propiciar. Diante deste entendimento, foi proposto para o Hack@UNIRIO o tema VIVÊNCIA UNIVERSITÁRIA, que recebeu a seguinte definição:

A VIVÊNCIA UNIVERSITÁRIA está relacionada às atividades que podem ser exercidas na universidade pela sua comunidade, que é composta por: professores, alunos, técnico-administrativos em educação e cidadãos interessados em contribuir com a universidade.

As atividades desenvolvidas pela universidade estão diretamente relacionadas ao Ensino, à Pesquisa, à Extensão e à Administração universitária.

A participação da comunidade nas instâncias deliberativas da
universidade através de conselhos, entre outros instrumentos
democráticos, também está associada à
UNIVERSITÁRIA.

Equipe: Os seguintes papéis foram elencados como necessários para conduzir o projeto de realização do evento: i) Coordenação Geral: responsável para coordenação geral do projeto e todas as atividades desenvolvidas durante o Hack@UNIRIO; ii) Coordenação de Infraestrutura Tecnológica: responsável pelo planejamento e gerenciamento da infraestrutura tecnológica necessária para o evento; iii) Coordenação de Infraestrutura Física: responsável pelo planejamento e gerenciamento da montagem do espaço físico necessário para a realização do evento; iv) Coordenação de Apoio e Patrocínio: responsável pelo planejamento e prospecção de apoiadores e patrocinadores para o evento; v) Coordenação de Alimentação: responsável pelo planejamento e gerenciamento da execução do serviço de alimentação durante o evento; vi) Coordenação de Metodologia e Processo: responsável pelo planejamento das metodologias e processos 
que serão empregadas durante o evento para sustentar a concepção e desenvolvimento das soluções, bem como o gerenciamento da execução das atividades baseadas nestes processos e metodologias; vii) Monitoria: indivíduos responsáveis por ajudar na execução das atividades referentes ao desenvolvimento das soluções durante o evento; viii) Mentoria: indivíduos que podem atuar na concepção e desenvolvimento das soluções; ix) Apoiadores: pessoas designadas para ajudar nas atividades operacionais do evento; $\mathrm{x}$ ) Coordenação Social: responsável pelo planejamento e gerenciamento da execução das atividades sociais do evento; xi) Coordenação de Comunicação: responsável pelo planejamento e gerenciamento das atividades de comunicação social do evento.

Embora esses papéis não tenham sido efetivamente desempenhados, pois as suas atividades poderiam ser realizadas por qualquer integrante da Comissão Organizadora ou por qualquer indivíduo da comunidade que se interessasse em executá-las; a definição desses papéis foi importante para nortear o conjunto de atividades que precisavam ser desenvolvidas, pois todas foram, de fato, executadas ao longo do projeto.

Partes interessadas: alguns aspectos sobre o perfil dos alunos do BSI, que, a princípio, iriam ser os mais motivados a participar do Hackathon, foram discutidos, como as habilidades relacionadas ao desenvolvimento tecnológico que eles possuem, a fluência em linguagens de programação, frameworks e ambientes de desenvolvimento. As informações sobre a fluência em tecnologias que os alunos do BSI possuíam foram obtidas por meio de conversas com professores do curso, como o conhecimento na linguagem de programação Java, não tendo sido elaborado um perfil detalhado das habilidades que tais alunos possuíam e que poderiam ser utilizadas para desenvolver os protótipos dos sistemas durante o evento.

Tempo: o calendário, a forma com que as atividades seriam desenvolvidas, presencialmente ou online, em quantos dias, o público-alvo, para toda a comunidade universitária da UNIRIO ou apenas direcionado para o CCET, também foram temas debatidos. A data de realização do evento que inicialmente estava definida para dezembro de 2016 foi alterada para o primeiro semestre do ano de 2017, pois no mês de dezembro as pessoas estão envolvidas em outras atividades, como a finalização do período letivo, o planejamento de férias e as festividades de final de ano. Houve a preocupação, também, de não realizar o evento em um feriado prolongado, pois as famílias aproveitam a oportunidade para viajar. A observação desses aspectos culturais é importante, pois do contrário a motivação dos indivíduos poderia, por exemplo, ser afetada pelas circunstâncias citadas.

Orçamento: a necessidade de captação de patrocinadores também foi objeto de conversas, pois o escopo do Hackathon dependeria, em parte, dos recursos disponíveis para serem empregados no projeto. A partir das atividades que se planejava realizar no Hack@UNIRIO e a observação de outros Hackathons, foi elaborada a planilha orçamentária com as seguintes categorias de itens de despesa: Instalações Físicas, Mobiliário, Material de Escritório, Material de Limpeza, Serviços de Apoio, Alimentação, Material Impresso, Prêmios e Brindes, e Vestuário. Com base nesta planilha, as modalidades de patrocínio foram descritas, constando o valor de cada cota e a contrapartida oferecida para os apoiadores.

Infraestrutura: visando montar um espaço multiuso dedicado às necessidades que estavam sendo vislumbradas para o Hackathon, foi projetado um espaço para comportá-lo. O objetivo era ter uma área que comportasse todas as atividades do evento 
e propiciasse uma interação intensa entre todos os envolvidos neste (participantes, organizadores, palestrantes, convidados e visitantes). A realização do Hack@UNIRIO, que ocorreu no CCET da UNIRIO, demandou o planejamento e a execução de diversas atividades operacionais para montar os espaços dedicados ao evento, sendo necessário preparar a sua infraestrutura de rede wireless e adaptar os espaços físicos para recepção, credenciamento, lanche, dormitório (os participantes pernoitaram no local) e para abrigar as equipes, onde o objetivo foi deixar as equipes em uma mesma sala para facilitar a convergência e a colaboração intra e inter equipe. As palestras e debates ocorreram nos auditórios do centro.

Comunicação: os seguintes sistemas foram utilizados para sustentar a condução do projeto: i) Facebook: foi criado um grupo fechado para possibilitar a interação entre os membros da equipe, mas foi encerrado, pois este espaço não era usual entre os integrantes da equipe, houve poucas interações; ii) WhatsApp: foi criado um grupo voltado para a organização do evento, onde a comunicação foi intensa e muito contribuiu para a coordenação das atividades em todas as etapas do projeto, foram feitas 1212 interações (mensagens postadas) por 25 membros até o dia da realização do evento; iii) Trello: o sistema foi utilizado para gerenciar as tarefas do projeto, onde as pessoas podiam se voluntariar em alguma tarefa, que foram organizadas no formato de quadro Kanban, sendo criadas 141 tarefas; iv) E-mail: foi criada uma lista de discussão por e-mail, sendo utilizada para discussão sobre diversos aspectos do projeto e gerenciamento das reuniões; v) Skype: utilizado para realização das reuniões, que foram, em sua maioria, semipresenciais, a equipe se reunia em uma sala de reuniões na UNIRIO e algumas pessoas participavam pelo Skype, foram realizadas 22 reuniões; e vi) Doodle: utilizado para agendar as reuniões do projeto, de forma que fossem contempladas as datas e os horário onde o maior número de pessoas pudesse comparecer.

Disseminação: em um evento no formato proposto para o Hack@UNIRIO, aberto e colaborativo - onde a participação no projeto é voluntária, os seus integrantes não são remunerados e os benefícios pessoais não são, a princípio, tangíveis - é importante definir uma estratégia para disseminar os propósitos da iniciativa, apresentando motivos para as pessoas se engajarem. O plano de disseminação para o evento foi centrado em um processo contínuo e permanente de comunicação, conduzido com o suporte dos seguintes meios de comunicação: site do Hack@UNIRIO, comunicação social da UNIRIO, e-mail, Página no Facebook, apresentações presenciais sobre o evento, incluindo conversas individuais, publicidade de boca-a-boca e cartazes em papel.

A página do evento no Facebook foi um importante veículo para a sua disseminação, sem usar nenhuma opção de promoção da página, apenas por meio da disseminação orgânica, a página alcançou 358 seguidores. O espaço foi utilizado para: apresentar os objetivos e informações sobre as atividades que seriam desenvolvidas no evento, as metodologias as quais este se baseava, quais eram os convidados, patrocinadores e apoiadores, auxiliar na cobertura de mídia e posteriormente apresentar os resultados do evento.

No intuito de manter a motivação das pessoas que participaram de alguma atividade do Hack@UNIRIO, fornecendo estímulos para que estes indivíduos continuem participando de iniciativas como a do referido evento, a página no Facebook foi mantida após a sua realização. Nesta página foram reportados os seus resultados e repercussão, e 
realizadas publicações sobre assuntos que estão associados ao que foi debatido sobre Vivência Universitária e sobre Hackathons.

\section{Realização do Hack@UNIRIO}

O público do Hack@UNIRIO foi constituído pelos seguintes atores: i) Organização do evento: integrantes Comissão Organizadora, apoiadores e pessoas contribuíram na operação do evento; ii) Patrocinadores: financiadores do evento; iii) Convidados: as pessoas que foram convidadas para fomentar o debate na Desconferência sobre Vivência Universitária, para ministrar palestras e alguns integrantes do Comitê Avaliador; iv) Participantes: pessoas que se inscreveram e foram aprovadas para atuar nas atividades de concepção e desenvolvimento de soluções tecnológicas para Vivência Universitária; e v) Visitantes: as pessoas que foram conhecer o evento, mas não praticaram nenhuma ação.

O evento recebeu setenta e duas inscrições, onde quase a metade, trinta e duas, eram de pessoas vinculadas à comunidade universitária da UNIRIO, entre alunos, professores e técnico-administrativos, e o restante eram membros de outras instituições de ensino e empresas do Estado do Rio de Janeiro e cidadãos que se interessaram pelo evento. A maioria das inscrições foram individuais, e cinco equipes foram inscritas. $\mathrm{O}$ quantitativo de inscritos que efetivamente participaram do evento foi de vinte e uma pessoas, compondo 5 equipes. Algumas inscrições não foram aprovadas pelo fato de as pessoas serem menores de idade.

As equipes foram compostas por alunos e docentes da UNIRIO e alunos de outras instituições de ensino, sendo que todas já estavam previamente formadas no ato da inscrição e receberam novos membros da universidade durante o evento, pois este era um pré-requisito. A jornada resumida do Hack@UNIRIO é apresentada na Figura 3.

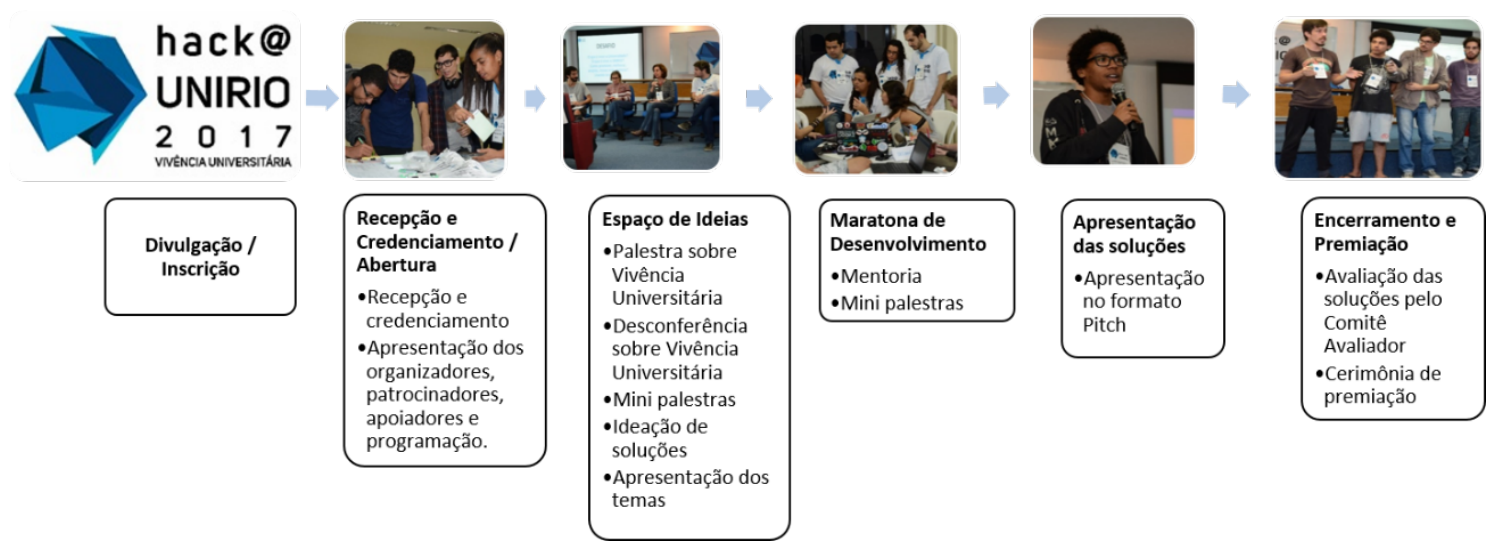

Figura 3 - Jornada do Hack@UNIRIO

\subsection{Abertura e Desconferência}

No dia 06 de maio do ano de 2017, em uma manhã de sábado de garoa fina na cidade do Rio de Janeiro, o Hack@UNIRIO teve início no Centro de Ciências Exatas e Tecnologia (CCET) da UNIRIO. A abertura do evento foi realizada no Auditório Tércio Pacitti, que foi preparado para abrigá-lo, este possui uma antessala, onde o público do evento pode se comunicar, se conhecer, falar sobre as suas atividades na universidade, seus interesses, entre outros assuntos, uma oportunidade de interação social. 
A abertura do evento foi realizada pela Professora Renata Araujo, que discorreu sobre a idealização do evento, os seus objetivos, o desafio que foi proposto, quem foram os seus organizadores, apoiadores e patrocinadores. A programação do evento também foi apresentada, juntamente com todas as pessoas que fizeram parte dela. $\mathrm{O}$ tema do Hack@UNIRIO, Vivência Universitária, também foi apresentado, abordando as questões que eram aderentes a este tema, quais eram as suas implicações e relevância para a UNIRIO. Esta apresentação foi o gatilho (ponto de engajamento) para engajar os presentes no tema do evento.

Após a palestra de abertura do evento foi iniciado o Espaço de Ideias, que foi constituído pela realização da Desconferência sobre Vivência Universitária e duas mini palestras. A apresentação da metodologia do Canvas da Proposta de Valor (CPV), foi uma das palestras, que já estava planejada, e a outra sobre o uso da API UNIRIO, cuja necessidade foi identificada durante a desconferência, pois despertou o interesse de muitos participantes. $\mathrm{O}$ formato de desconferência para debater a vivência universitária contribuiu para que houvesse um "rico" debate sobre o tema, pois este favoreceu a livre manifestação, de forma igualitária, de qualquer interessado.

Embora o auditório não possibilitasse muitas alterações no arranjo do seu espaço físico, o ambiente foi preparado para abrigar a desconferência. No intuito de aproximar o público do debate, as cadeiras onde as pessoas que fizeram interversões sentaram, foram posicionadas abaixo do palco, possibilitando o fácil acesso e tentando causar uma sensação de uma relação de igualdade (horizontalidade) entre todos os presentes no evento.

A conversa sobre Vivência Universitária foi iniciada com as seguintes provocações:

O que é viver a Universidade? O que é viver a UNIRIO? Como promover, melhorar, ampliar, inovar esta vivência? Usando tecnologia?

Os debates foram inaugurados com a exposição das dificuldades vivenciadas pelo aluno ao ingressar na universidade, pois esta possui regras que estão expressas em diversos documentos, como regulamentos, estatutos, portarias, entre outros, de forma explícita e implícita, e estes não são de fácil compreensão pela sua comunidade. Isso ocorre tanto com alunos ingressantes, quanto com professores que já são membros da universidade há algum tempo, situação que é agravada quando o aluno é o primeiro do seu núcleo familiar a ingressar neste universo.

O uso das tecnologias como um instrumento de socialização, capaz de reunir as pessoas, ao invés de dividir (polarizar), respeitando as suas diferenças, suas crenças, preferências, também foi destacado. Conforme foi relatado, tem-se buscado desenvolver processos mais afetivos, solidários, para a afiliação dos estudantes que recém adentraram na UNIRIO, de maneira que este percurso seja menos sofrido. Algumas oportunidades de desenvolvimento de sistemas também foram apontadas, como um sistema para dispositivos móveis (aplicativo) que possibilitasse saber a localização dos ônibus da universidade.

De que forma a inovação tecnológica e inovação social podem contribuir para melhorar a experiência vivenciada na universidade? Esta foi uma das indagações, sendo destacado que a inovação social tem o objetivo de promover transformações em uma comunidade, desta maneira, as soluções voltadas para inovação social podem contribuir 
para melhorar a vivência na universidade. Neste sentido, é vislumbrada a necessidade dos diversos atores da universidade se reconhecerem como inovadores, o que não ocorre facilmente em projetos relacionados à inovação social. Por isso, não é constituída uma rede, onde estes múltiplos atores poderiam atuar conjuntamente em projetos que possuem objetivos semelhantes.

A desconferência foi, também, uma oportunidade para que os diversos membros da universidade discorressem sobre os projetos que estão envolvidos, expondo as suas potencialidades e problemas, frustrações, que vivenciam para conduzir estes projetos, que estão associados a várias questões, como a falta de processos organizacionais para suportar as demandas destes projetos e infraestrutura não adequada para acomodá-los. As pessoas que já tinham projetos idealizados ou em andamento, também aproveitaram esta oportunidade para tentar captar pessoas para trabalhar nestes projetos.

O Hack@UNIRIO como uma oportunidade da comunidade universitária da universidade se conhecer melhor, propiciando a interação de diversos atores, de propiciar que pessoas externas à sua comunidade conheçam a UNIRIO e desenvolver soluções tecnológicas, foi uma das falas de um dos convidados para a desconferência. A colaboração no processo de desenvolvimento tecnológico, entre os diversos atores, grupos e unidades organizacionais da universidade, foi exposta como uma importante necessidade.

Foi feita uma breve apresentação dos recursos de TIC disponíveis na UNIRIO, que poderiam ajudar no desenvolvimento das soluções tecnológicas, estes recursos são: o servidor LDAP (Lightweight Directory Access Protocol), que possibilita que as credenciais de sistema (usuário e senha cadastrados no sistema de gestão) das pessoas vinculadas à UNIRIO sejam autenticadas; e API UNIRIO, o sistema desenvolvido pelos integrantes da DTIC no formato de API (Application Programming Interface), que facilita a interoperabilidade entre sistemas e possibilita o acesso à alguns dados institucionais da universidade. Destacou-se que os referidos dados ainda não estão sendo disponibilizados no formato de dados abertos, pois o Plano de Dados Abertos (PDB) da UNIRIO ainda não foi aprovado na instituição.

A dificuldade em habitar a UNIRIO foi explicitada. Foi reportado que seus espaços dificultam a convivência entre os indivíduos da sua comunidade, sendo necessário realizar melhorias na sua infraestrutura física e de TIC, para que o seu espaço físico e ciberespaço sejam mais acessíveis à sua comunidade. Uma solução tecnológica que possibilite a otimização do uso destes espaços foi suscitada.

As más (traumáticas) experiências vivenciadas nas universidades também foram relatadas, sendo associadas à falta de integração intra-universitária, distanciamento da realidade vivenciadas pelos alunos nas empresas, criando um ambiente que não incentivava a inovação. Outra questão abordada foi que a vivência universitária começa fora da universidade, já começa com o processo de escolha da universidade, por isso os projetos devem considerar esse cenário externo.

Uma visão positiva sobre as normas (burocracia) presentes na universidade também foi apresentada. Entende-se que estas ajudam as decisões a serem mais justas e a evitar fraude. Mesmo com os diversos problemas que as instituições públicas de ensino superior possuem, estas são, em muitos casos, o melhor espaço habilitado por alguns 
alunos, e que a intensificação do uso de TIC para prover acesso ao conhecimento pode beneficiar os alunos vulneráveis socialmente.

O contexto político também foi abordado, trazendo provocações sobre como as tecnologias podem ser usadas para aumentar o engajamento político, dar mais argumentos para o cidadão protestar, reivindicar em todos os cenários, seja na universidade, no município ou a nível estadual e nacional, pois os contextos são similares. O problema da comunicação interna na universidade também foi explicitamente citado, sendo a UNIRIO comparada a um castelo feudal, onde cada departamento tem o seu castelo, o seu feudo, não havendo uma comunicação adequada.

O esforço dos professores do Bacharelado em Sistemas de Informação (BSI) da UNIRIO para integrar os alunos do curso à universidade, aos projetos do curso, foi elogiado. Foram indicadas como soluções para melhorar a vivência, o desenvolvimento de um repositório unificado para o gerenciamento de oportunidades, bem como uma maior integração entre as empresas juniores. A dificuldade do transporte urbano (interno e externo) na UNIRIO também foi debatida.

Durante a desconferência foi elaborado um mapa mental que sintetiza as informações explicitadas durante os debates. Estas informações se referem aos cenáriosproblema vivenciados na UNIRIO (dores), oportunidades advindas destes cenários e alguns recursos, que podem ser utilizados no desenvolvimento das soluções para amenizar os problemas advindos destes cenários, e algumas restrições que foram apresentadas pelos participantes. Desta forma, possibilitou-se que as equipes conhecessem mais sobre os problemas associados à Vivência Universitária e fossem mais empáticas a este tema.

\subsection{Ideação}

A exposição do Canvas de Proposta de Valor, durante o espaço de ideias, teve o objetivo de apresentar para os participantes um instrumento que poderia ajudá-los a conceber as soluções tecnológicas. Este canvas os leva a refletir sobre quais são os problemas (dores) vivenciados pelos clientes da solução em relação a um conjunto de atividades que eles desejam realizar, que benefícios eles gostariam de alcançar; e diante deste mapeamento, quais são os produtos e serviços que poderiam ser desenvolvidos para amenizar estas dores.

A mentoria inicial foi realizada pelos integrantes da Diretoria de Tecnologia da Informação e Comunicação (DTIC), que conversaram com todas as equipes, algumas demonstraram o desejo de usar os recursos da API UNIRIO na implementação das suas soluções tecnológicas. Houve uma conversa com as equipes sobre a importância de desenvolver soluções tecnológicas inclusivas e acessíveis, pois desta forma estas podem ter maior alcance, o que se torna mais relevante em um ambiente tão diversificado como a UNIRIO.

Durante a maior parte do tempo reservado ao desenvolvimento dos protótipos das soluções tecnológicas, também ocorreu a evolução do desenho (escopo) destas soluções. Nesta jornada ocorreu o maior detalhamento de quais problemas as soluções pretendiam resolver ou amenizar e quais seriam os recursos utilizados, quais eram os seus potenciais clientes, se as premissas as quais estas se basearam eram coerentes, e alguns aspectos da 
operação e sustentação dos serviços que poderiam ser constituídos a partir destas soluções também foram discutidos.

Diversos fatores contribuíram para evolução do desenho das soluções tecnológicas, entre estes: i) Interação intra e inter equipes: à medida que as soluções eram desenvolvidas, o que impunha aos participantes, em certa medida, o aprofundamento do conhecimento sobre o tema, novos insights eram gerados, o que resultava em novas aplicações e funcionalidades para as soluções tecnológicas; ii) Mentoria: as conversas entre os mentores e as equipes, além de fornecer informações sobre os possíveis cenários de uso das soluções em desenvolvimento, sanar dúvidas conceituais sobre os temas, sobre as regras do evento e sobre algumas questões tecnológicas, também incentivaram a autorreflexão sobre as soluções tecnológicas que estavam sendo propostas, ou seja, que os integrantes da equipe fizessem questionamentos sobre a solução que estavam desenvolvendo.

\subsection{Maratona de Desenvolvimento}

O desenvolvimento dos protótipos das soluções tecnológicas que foram propostas pelas equipes foi iniciado assim que as equipes definiram os seus temas, não sendo identificada a construção de protótipos de baixa fidelidade, que representassem os conceitos inerentes a estas soluções e possibilitasse que estas fossem validadas. Verificou-se desde o início da jornada de desenvolvimento, que as equipes estavam focadas em desenvolver as versões finais das suas soluções tecnológicas, de forma que todas as funcionalidades que estavam sendo especificadas fossem implementadas.

Algumas intervenções foram realizadas em relação à fidelidade dos protótipos de sistemas que estavam sendo desenvolvidos, pois embora uma das questões a serem avaliadas fosse as funcionalidades implementadas, de forma que o usuário pudesse realizar a tarefa inerente a esta no sistema, o mais importante era apresentar um protótipo que refletisse a solução que foi desenhada. Portanto, mais importante que ter um determinado recurso do sistema funcionando e vários outros que sequer foram representados, era melhor ter a solução tecnológica proposta plenamente representada, mesmo que algumas funcionalidades não tivessem sido completamente implementadas.

As TIC utilizadas pelas equipes para desenvolver as soluções foram de sua livre escolha, e estas optaram pelo uso de linguagens de programação e frameworks para desenvolvimento de sistemas que tinham maior familiaridade, conforme pode ser identificado por meio das habilidades que estes declaram ter ao realizar a inscrição para o evento. Os recursos utilizados foram: linguagens de programação C++, HTML, PHP e JavaScript; os frameworks NodeJS, NPM, Shiny e Composer; e API UNIRIO.

Um aspecto importante na maratona foi a auto-organização das equipes, as tarefas foram compartilhadas entre os seus membros de acordo com o seus interesses e habilidades, alguns foram direcionados para programar o back-end e front-end, enquanto outros membros atuavam no desenho (especificação) da solução. O altruísmo foi identificado entre os participantes, houve cooperação inter equipes, alguns participantes se dispuseram a ajudar as outras equipes a finalizarem os seus projetos e a superar dificuldades em relação a tangibilização das soluções (desenvolvimento dos protótipos).

Essa interação foi facilitada pela forma com que os espaços foram montados, os participantes estavam todos na mesma sala e cada equipe tinha um facilitador, cuja missão 
era atuar na comunicação interna e externa (com outras equipes e mentores) da equipe. A autogestão foi identificada até no revezamento de descanso entre os integrantes das equipes e ao colocarem música durante a madrugada para "espantar" o sono e continuarem trabalhando nos seus projetos.

Ao final de quase 30 horas ininterruptas de atividades, o Hack@UNIRIO chegou a sua etapa final, e as cinco equipes que percorreram a sua jornada puderam apresentar os resultados dos seus esforços. As soluções tecnológicas, que foram desenvolvidas ou aperfeiçoadas durante o evento serão descritas a seguir, com base no que foi observado durante todo o evento, principalmente na apresentação das soluções pelas equipes. Os código-fonte de todos os protótipos das soluções tecnológicas estão disponíveis no repositório do evento no GitHub.

No primeiro dia do Hackathon, com o objetivo de auxiliar as equipes no planejamento das apresentações, foi ministrada uma palestra sobre como fazer apresentações no formato pitch, que é uma apresentação rápida, com duração em torno de cinco minutos. A montagem das apresentações foi influenciada pela estratégia de apresentação sugerida nesta palestra, com o seguinte roteiro: Introdução, Problema, Potencialização do Problema, Solução e Visão.

As soluções apresentadas pelas equipes foram avaliadas pelo Comitê Avaliador do Hack@UNIRIO, que fez questionamentos sobre estas e já indicou algumas melhorias futuras a serem feitas nas propostas apresentadas. O comitê, composto por membros da UNIRIO, profissionais de outras organizações e empreendedores, que compuseram um comitê multidisciplinar, avaliou se os pré-requisitos descritos no Regulamento do evento para o desenvolvimento das soluções foi observado pelas equipes e se as soluções estavam aptas a serem avaliadas, ou seja, se foram apresentadas e o código-fonte gerado foi disponibilizado no repositório do evento. As soluções foram avaliadas de acordo com os seguintes critérios: aderência ao tema do evento, grau de inovação, user interface e user experience.

\subsection{Soluções Tecnológicas Criadas}

A equipe No Fun Allowed projetou a solução tecnológica denomina "Uniriobot" com o objetivo de facilitar e centralizar o acesso às informações institucionais pela comunidade universitária da UNIRIO por meio do sistema de conversação Facebook Messenger. A solução é composta por um chatbot, que foi desenvolvido pela equipe para possibilitar a interação com a comunidade. Ao apresentar a solução, os seus idealizadores argumentaram que o Facebook é mais usado que os outros meios de divulgação utilizados na universidade, como o Telegram, desta forma o "Uniriobot" se apresenta como um instrumento mais efetivo para ter acesso a informação e até solicitar algum serviço com maior agilidade.

O desejo de unir pessoas que desejam compartilhar o conhecimento sobre o conteúdo de uma disciplina de um curso da UNIRIO, foi a motivação da equipe Baixada Coders para desenvolver a solução denominada "Mentori”. Esta solução, baseada em um sistema web, promove o encontro das pessoas que têm dificuldade em uma determinada disciplina com pessoas que estão dispostas a ajudar. Com isso, caso um indivíduo esteja interessado em receber uma mentoria de uma disciplina do curso, ele pode dar um match na oferta de mentoria daquela disciplina, caso haja. No intuito de evitar fraudes, o processo de oferta de mentoria foi semi-anonimizado, de maneira que as pessoas que 
estão procurando uma oferta não saibam quem as disponibilizou, e somente a partir do aceite pelo ofertante, que os contatos serão disponibilizados para que as pessoas possam interagir fora da plataforma, pois a equipe argumentou que a interação na plataforma não iria ser muito eficiente, já que as pessoas estão habituadas a usar outros meios de conversação.

Como incentivo para o uso do "Mentori", os ofertantes são avaliados ao final da mentoria e esta avaliação pode ser utilizada como critério para concessão de bolsas de monitoria. Foi idealizada, também, a possibilidade do uso de modelo de coins (moedas virtuais), onde os alunos que oferecerem ajuda seriam bonificados com essas moedas, que poderiam ser transformadas em horas curriculares. A solução permitiu a inclusão social e a diversidade de gênero pela inclusão do campo nome social no cadastro de usuário, cujo uso já é regulamentado em algumas universidades.

As dificuldades que os alunos enfrentam ao ingressar em uma universidade inspiraram a equipe Decoders a idealizar a solução que foi denominada "Adote um Calouro". A plataforma tem objetivo de promover a socialização de ingressantes à vida universitária, visando a diminuição da evasão de alunos nos primeiros períodos do curso. Os índices significativos de evasão nas universidades foram apresentados, em torno de $50 \%$, assim como a estimativa de perda de recursos financeiros em função da evasão.

Essa realidade foi vivenciada por uma das integrantes da equipe que não conseguiu concluir o curso de graduação, e ingressou em um novo curso. Foi exposto que são vários os fatores que motivam as pessoas a ingressarem em uma universidade, viver experiências diferentes é um deles, como se dedicar a coisas que gosta de fazer, criar novas amizades, participar de festas, torna-se membro de clubes de fraternidade, entre outras possibilidades. Em muitos casos esse desejo é frustrado pelas diversas responsabilidades e compromissos que são impostos aos alunos ao ingressar em um curso de graduação. A plataforma, baseada em um sistema web, foi idealizada para possibilitar que o aluno ingressante cadastre o seu perfil, por meio do fornecimento de informações sobre as suas preferências, informações acadêmicas, disciplinas que está cursando, entre outras, e com isso os alunos veteranos que acessarem a plataforma podem decidir adotar um calouro por um semestre. Como planos futuros, foi previsto a elaboração dos termos de uso e a utilização da API UNIRIO.

A equipe DATA UNIRIO optou por dar continuidade a um projeto ao qual já estavam engajados, que visa empoderar a todos os interessados na universidade, no tocante à transparência de dados e apoio à gestão nas tomadas de decisão. O sistema web desenvolvido pela equipe, que foi aperfeiçoado durante o Hackathon, tem o objetivo de tornar mais transparente o orçamento da UNIRIO, de forma que os não especialistas consigam compreendê-lo com maior facilidade; o sistema apresenta os dados utilizando o método de treemapping. O maior envolvimento dos membros da comunidade universitária em relação à execução orçamentária também é um dos alvos do projeto. A equipe, que foi composta por dois professores e um aluno da UNIRIO, apresentou a visão de que as universidades, como um ambiente de aprendizagem, não têm o foco apenas no conhecimento técnico e na formação de profissionais, que estas devem ter um olhar, também, na formação cidadã.

A proposta da equipe Campus Comunidade foi relacionada a promoção da integração entre projetos sociais em andamento nas comunidades e projetos desenvolvidos nas universidades, em um formato inspirado em sistemas de marketplace, 
onde se reúne em uma mesma plataforma diversos fornecedores de produtos e os consumidores interessados nestes.

\subsection{Avaliação}

Após a realização do Hack@UNIRIO foram enviados questionários para as pessoas que atuaram na sua organização e para os participantes do evento, incluindo as pessoas que participaram integralmente e as que estiveram em apenas algumas atividades do evento ou não foram. Os questionários foram elaborados com o objetivo de identificar os aspectos motivacionais dos participantes e dos integrantes da organização do evento, e em relação ao formato do evento, sobre o quanto as atividades que foram propostas para o Hackathon contribuíram para o desenvolvimento das soluções tecnológicas. O questionário enviado para os integrantes da organização recebeu 6 respostas, o direcionado aos participantes recebeu 10 e o enviado para os indivíduos que não participaram integralmente ou não foram, recebeu 14 respostas.

Do ponto de vista dos organizadores, as seguintes sugestões foram mencionadas em relação ao formato do evento: extensão dos dias do evento, possibilitar somente a inscrição por equipes, sem limite de idade e com a permanência obrigatória durante todo o evento, não ter um tema previamente definido, propondo que este emerja durante o Hackathon, e concentrar esforço para ter mais participantes da UNIRIO. Todos os respondentes explicitaram que o Hack@UNIRIO contribuiu para o seu desenvolvimento pessoal e profissional, e estão dispostos a trabalhar na organização do próximo evento. Em relação ao desenvolvimento pessoal, a seguinte resposta é destacada:

[..] conhecer outras pessoas e realidades, outros pontos de vista, isso acrescenta muito pra nossa vida, nos faz evoluir como gente e ter mais empatia.

Os respondentes consideraram que o Hack@UNIRIO gerou os seguintes benefícios para a comunidade universitária: a maior integração entre os membros da comunidade, proporcionando a explicitação dos problemas vivenciados, de pesquisas em andamento, bem como o despertar do sentimento de pertencimento e de que a UNIRIO tem capacidade para desenvolver bons eventos, assim como as soluções que foram desenvolvidas durante o Hackathon. As seguintes respostas são destacadas:

Integração de professores e alunos de diferentes departamentos; visibilidade da Universidade no meio acadêmico, participaram alunos de várias universidades; Integração dos alunos de graduação, mestrado, doutorado e professores; Constatação de que podemos fazer um evento de qualidade.

Além das soluções tecnológicas implementadas (que espero que sejam efetivamente implantadas), acho o maior ganho foi a integração entre diferentes setores/áreas da Universidade. Eu particularmente pude conhecer muitas ações e pesquisas que até então desconhecia.

Do ponto de vista dos participantes,o Hack@UNIRIO foi visto como um evento que poderia contribuir para que os participantes alcançassem múltiplos objetivos, como o desejo de vivenciar a experiência de participar de um Hackathon, ampliar a rede de contatos profissionais e pessoais, conseguir parceiros para os projetos e viabilizá-los. 
Diversas atividades foram consideradas como importantes para o desenvolvimento das soluções tecnológicas, principalmente a Desconferência sobre Vivência Universitária, que possibilitou a identificação dos problemas, e o diálogo com os mentores do evento. Entre os impedimentos, o tempo para o desenvolvimento das soluções tecnológicas foi o mais destacado.

Dentre os facilitadores para o desenvolvimento das soluções, foi destacado o ambiente acolhedor, com infraestrutura adequada, a interação com os mentores e o trabalho colaborativo desenvolvido nas equipes. Entre as sugestões para o próximo Hackathon, destaca-se o desejo de continuar na temática de algumas soluções que foram desenvolvidas pelas equipes e que tenham mais palestras e tempo para o desenvolvimento das soluções, todos os participantes explicitaram ter interesse em trabalhar na evolução das soluções que foram desenvolvidas pelas suas equipes. Os participantes consideraram que o evento contribuiu para que eles ampliassem o entendimento sobre os problemas vivenciados pela comunidade universitária da UNIRIO e que contribuiu para o desenvolvimento pessoal e profissional deles. Todos manifestaram o desejo de participar da próxima edição do evento.

Entre os indivíduos que participaram somente de algumas atividades ou não foram ao evento, foram vários os motivos apresentados. Dentre estes, destaca-se o sentimento de que não poderiam atuar na ideação e desenvolvimento das soluções tecnológicas, desta forma, alguns indivíduos participaram apenas da desconferência. As seguintes visões opostas são apresentadas a seguir, de um indivíduo que não é de um curso de computação, mas participou integralmente do evento (Participante 1), e de um indivíduo (Participante 2) que também não possui formação em uma área tecnológica, mas não participou do desenvolvimento da Maratona de Desenvolvimento:

[..] estou bem mais confiante nas minhas habilidades e agora sou capaz de me visualizar como alguém capaz de desenvolver essas soluções ou seja, o intangível se tornou tangível. Em outras palavras, compreendi emocionalmente que não existe diferença entre 'desenvolvedores' e 'eu'. Estou me sentindo bem.

Participante 1

O evento desde o início mostrou ter o objetivo de desenvolvimento tecnológico. O qual não pude visualizar como minhas habilidades como cinegrafista, fotógrafo e editor poderiam ser úteis para a elaboração dos projetos.

Participante 2

\section{Reflexões sobre a pesquisa-ação}

Nesta seção, apresentamos a análise dos resultados obtidos às questões formuladas pela pesquisa, a saber: como desenvolver TICs para possibilitar a participação social no âmbito das instituições públicas com a contribuição da sociedade; quais seriam as características observadas dos sistemas desenvolvidos por meio desta atuação conjunta; e como se daria a motivação para atuar nestas atividades.

A pesquisa-ação desenvolvida foi projetada para observar, portanto, as seguintes questões específicas relativas à jornada do Hack@UNIRIO: i) Trajetória projetual: está relacionada à descoberta das etapas, atividades, recursos e artefatos necessários para realização de um Hackathon aberto e colaborativo, em uma Instituição Federal de Ensino 
Superior (IFES) com o objetivo de desenvolver AVPS; ii) Engajamento dos participantes: refere-se à compreensão de como ocorreu o engajamento dos indivíduos da comunidade universitária para participar do Hackathon com o propósito de desenvolver AVPS voltados para o cenário desta comunidade; e iii) Características dos AVPS: refere-se à compreensão das características dos AVPS idealizados e desenvolvidos com a participação ativa da comunidade universitária.

Os objetivos do Hack@UNIRIO foram alcançados, cinco protótipos de sistemas caracterizados como AVPS foram desenvolvidos, mas além deste propósito, diversos outros benefícios em relação a participação social foram identificados. A jornada do evento possibilitou a identificação de atividades inerentes a realização do um Hackathon no âmbito de uma universidade pública, alguns aspectos motivacionais relacionados a participação dos indivíduos, tanto na organização quanto nas atividades que foram propostas para o evento, e também as características dos AVPS desenvolvidos, que foram aderentes ao tema do evento.

A organização e realização do Hack@UNIRIO se apresentou como uma iniciativa de participação social, pois possibilitou que a comunidade universitária da UNIRIO debatesse abertamente sobre diversos temas relacionados à universidade, que diversos atores buscassem, conjuntamente, soluções para resolver alguns problemas que foram expostos e, em certa medida, conseguiu influências na tomada de decisão da universidade, bem como expuseram algumas demandas para as instâncias gestoras da universidade, como a necessidade de haver maior integração entre todos atores da universidade. Nas seções a seguir discutimos as principais reflexões desta pesquisa-ação.

\subsection{Trajetória Projetual}

A realização do Hack@UNIRIO foi uma tarefa desafiadora em função de diversos fatores, destacando-se: i) A conjuntura político-econômica-social do Brasil: o país passava por um conturbado cenário político, onde houve a substituição da um Presidente da República por meio de um processo de impeachment. Em meio a este cenário, vivenciava-se, também, uma crise econômica, e por consequência uma crise social. Essas questões afetam as instituições públicas, pois, em geral, este cenário implica em mudanças nos Programas de Governo já estabelecidos, alcançando políticas públicas e serviços públicos. Por consequência, esses acontecimentos podem influenciar na relação das instituições públicas com o cidadão, que tende a ser mais problemática, pois os dois atores estão em processo de adaptação em relação a um novo contexto.

Os outros fatores foram: ii) O pioneirismo: o fato de os idealizadores do projeto nunca terem organizado uma Hackathon na UNIRIO, sendo o primeiro com estas características a ser realizado nesta instituição, se constituía como uma fragilidade do projeto, com vários riscos a serem superados, conforme foi descrito no Plano de Projeto do Hackathon. iii) A cultura preexistente: conforme apresentado na contextualização do cenário da UNIRIO em relação às questões que eram objeto de observação desta pesquisaação, a participação da comunidade universitária não era habitual em relação às questões de interesse coletivo associadas à universidade. No contexto do BSI também não era pujante a cultura de participação em maratonas hackers, em algumas universidades os alunos são incentivados a participar destas maratonas.

O Hack@UNIRIO foi idealizado para ser um meio para possibilitar a concepção e o desenvolvimento AVPS com a participação da comunidade universitária, e com isso 
ampliar a participação social na UNIRIO. A cooperação da comunidade era vista como uma oportunidade de desenvolver AVPS que tivessem maior efetividade no contexto da universidade, pois a cooperação direta dos indivíduos que vivenciam os problemas poderia contribuir para desenhar soluções centradas nas suas reais necessidades, em uma perspectiva bottom-up, onde a comunidade teria maior protagonismo. O pesquisador já havia experimentado o desenvolvimento de um AVPS, o Ouvidoria Social, especificado a partir das características de outros sistemas com os mesmos objetivos, em uma visão top-down, sem considerar o seu contexto de uso, e houve dificuldade na sua aceitação, o seu uso foi bem restrito.

Ao longo do projeto, a visão do Hackathon como meio foi se transformando em uma visão do Hackathon como um mecanismo de participação social, tanto em relação ao seu planejamento e organização colaborativos, quanto em relação à sua realização. $\mathrm{O}$ Hack@UNIRIO propiciou a interação social entre indivíduos de diversos segmentos da UNIRIO, alunos, professores e técnico-administrativos, e também de pessoas externas à instituição, que contribuíram em várias etapas do projeto. Durante o planejamento do evento, a priori, todos estavam no papel de cidadãos que se voluntariam para realizar um Hackathon, contribuindo com o conhecimento que possuíam sobre maratonas hackers, sobre as experiências que vivenciavam na universidade, entre diversos outros conhecimentos que poderiam contribuir para a realização do evento. $\mathrm{O}$ ecossistema social formado durante a jornada do evento é apresentado na Figura 4.

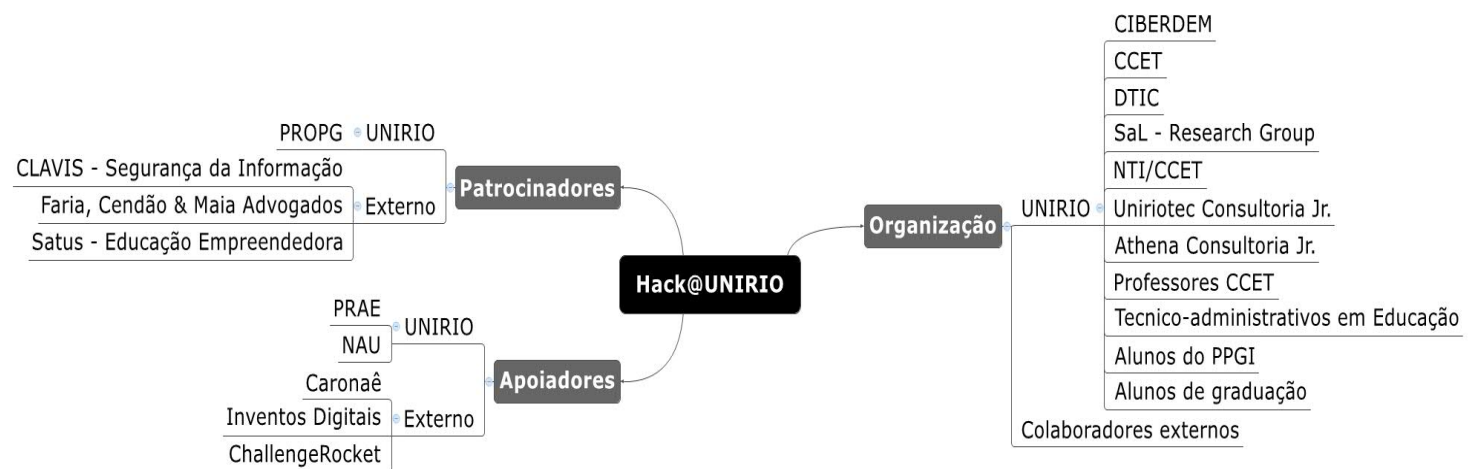

Figura 4 - Ecossistema social formado na jornada de realização do Hack@UNIRIO

O planejamento do Hack@UNIRIO proporcionou uma aprendizagem cooperativa sobre como fazer um evento aberto e colaborativo para propor e desenvolver soluções tecnológicas no ambiente de uma Instituição Federal de Ensino Superior (IFES), sendo o envolvimento de diversos atores da universidade um aspecto muito importante para a concretização do projeto. As relações e processos em uma universidade pública se apresentam como questões complexas, não sendo de fácil compreensão para serem mapeadas ou generalizadas, por isso a inteligência coletiva, proporcionada pelo engajamento da comunidade universitária da UNIRIO se constituiu como um fator crítico de sucesso para a realização do Hackathon.

Diante da experiência vivenciada na jornada do projeto de realização do Hack@UNIRIO, indica-se a observação de um conjunto de atividades ao planejar a realização de um Hackathon no âmbito de uma instituição pública de ensino. Em relação às etapas que foram incialmente propostas (Imersão, Ideação e Prototipação), baseadas nas fases de desenvolvimento de soluções inovadoras propostas a partir do Design Thinking, a etapa Imersão, onde foi realizada uma desconferência, mostrou-se essencial 
para a ideação das soluções tecnológicas, e foi além, promoveu a integração entre os diversos atores da universidade e externos a esta. No caso da Ideação e da Prototipação, onde não foram planejadas atividades específicas, apenas sugerido o uso da metodologia do Canvas da Proposta de Valor (CVP), não foi identificada uma separação significativa da atividade de ideação e de prototipação, tudo ocorreu simultaneamente, sendo a ideação muito influenciada pelas experiências vivenciadas pelos sujeitos e pelo que foi explicitado durante a Imersão.

A partir dessa reflexão, é proposto que os Hackathons com as características da Hack@UNIRIO, aberto, colaborativo e interdisciplinar, voltados para questões de interesse público, tenham as seguintes etapas: Imersão e Ideação, Construção, Evolução e Experimentação. Na Imersão e Ideação são realizadas as atividades imersivas, que buscam explorar questões relacionadas ao tema do evento e explicitar os problemas advindos dos cenários descobertos, a desconferência se mostrou uma boa técnica para realizar isso em Hackathons, podendo ser combinadas com outras técnicas, como entrevistas de campo.

Após a realização da imersão devem ser realizadas apenas atividades de ideação dos projetos, das soluções, pois desta forma podem surgir mais ideias, aumentando a possibilidade de que as melhores ideias emerjam, ao invés da primeira ideia viável. A proposta é que essas atividades sejam realizadas em um dia do evento, podendo ser, por exemplo, as atividades de imersão presenciais e a geração de ideias online.

A etapa Construção deve ser inteiramente dedicada à construção de protótipos funcionais, com isso as ideias poderiam ser validadas por meio destes protótipos e outros aspectos referentes a estes poderiam ser melhor definidos, como a interação humanocomputação (usabilidade, acessibilidade, comunicabilidade e experiência do usuário). Esta etapa deve ser realizada presencialmente no formato tradicional de maratona hacker, e os idealizadores comporiam as equipes, independentes do conhecimento que estes tenham de desenvolvimento de soluções tecnológicas. Na Evolução e Experimentação, como já foi proposto, os protótipos são transformados em produtos.

\subsection{Engajamento}

Desde o início do projeto de realização do Hack@UNIRIO houve a preocupação com o engajamento da comunidade universitária da UNIRIO, se as oportunidades apresentadas seriam suficientes para que as pessoas se motivassem a participar do Hackathon. Estas oportunidades eram: a possibilidade de propor soluções de base tecnológica que poderiam produzir mudanças reais nas atividades das universidades, em um formato de evento que privilegiaria a interdisciplinaridade, colaboração e livre participação, sem intermediários.

Inicialmente, as conversas estavam voltadas para os participantes, indivíduos que participariam da idealização e desenvolvimento das soluções tecnológicas, mas foi percebido que era necessário engajar a comunidade para também participar da organização do evento. Com isso, algumas ações passaram a ser propostas para alcançar esses dois objetivos, aumentar a equipe organizadora e motivar as pessoas a participar do evento.

Buscou-se o apoio de alguns atores da UNIRIO que se constituíam como referência e que também poderiam contribuir para a sustentação do projeto de realização do Hack@UNIRIO, como: as representações discentes, as unidades acadêmicas, 
administrativas e gestoras da universidade associadas aos propósitos do evento, como a Pró-Reitoria de Assuntos Estudantis (PRAE), o Centro de Ciências Exatas e Tecnologia (CCET) e a Diretoria de Tecnologia da Informação e Comunicação (DTIC). O envolvimento destes atores contribuiu para a disseminação dos propósitos do Hack@UNIRIO, para aproximar o evento da realidade da universidade, a influenciar a comunidade a contribuir com o evento e amenizar fatores que se constituem como barreiras motivacionais, por exemplo, a sensação de que os projetos não terão continuidade.

\subsection{Integrantes da Organização}

Ao iniciar o planejamento do Hack@UNIRIO, esperava-se que haveria um grande interesse dos indivíduos da UNIRIO cujas pesquisas abrangiam a relação entre os cidadãos e as instituições públicas, melhorias nos processos organizacionais destas instituições, na prestação de contas, entre outros temas de pesquisa relacionados à governo. No entanto, isso não ocorreu, embora tenham havido significativas contribuições, a cooperação no projeto não foi contínua. Talvez isso tenha ocorrido em função das agendas de pesquisa não incluírem a cooperação dos pesquisadores em ações práticas, o pesquisador atua como um observador, não intervém na realidade.

A habitualidade em participar de maratonas hackers, como Hackathons e game jams, foi uma característica identificada em alguns indivíduos que se motivaram a integrar a Comissão Organizadora do Hack@UNIRIO, independentemente do papel que exerciam na universidade. No questionário enviado para os participantes, um dos respondentes expressou a vontade de participar da próxima edição do evento compondo a equipe de apoio, um indício de que ao se envolver no universo de Hackathons, as pessoas se motivam a participar de outros eventos neste formato.

Observou-se que o envolvimento dos integrantes não foi contínuo. $\mathrm{O}$ ingresso de novos sujeitos ao projeto ao longo de sua jornada também é um aspecto que merece atenção, pois embora seja visto como muito benéfico, o projeto precisa estar preparado para acomodar estes ingressantes, de forma que os novos integrantes sejam atualizados sobre toda a trajetória do empreendimento e de ações futuras. Desta forma, os efeitos deste engajamento ad-hoc, por assunto, podem ser amenizados.

Identificou-se, e foi explicitado por alguns indivíduos, que além de contribuir com uma causa maior, que eram os objetivos definidos para o evento, alguns indivíduos também tinham propósitos pessoais, que poderiam ser alcançados por meio do deste. Estes interesses podem ser benéficos, caso não subvertam os propósitos primários do Hackathon, sendo ampliadas as motivações extrínsecas, com alguns benefícios que não haviam sido identificados pela organização do evento, incentivando o engajamento de outros sujeitos.

Aspectos relacionados à carreira também foram identificados como alavancas para alguns indivíduos se integrarem à organização do evento, pois figurar como organizador de um Hackathon foi visto como uma atividade que poderia ser destacada no currículo. A possibilidade de utilizar a participação no evento como atividade complementar, que são exigidas nos cursos de graduação, também se apresentou como uma motivação extrínseca. 
Ao observar o comportamento de todas as pessoas que atuaram de alguma forma na organização do Hack@UNIRIO e conversas com alguns indivíduos, foi percebido que - o sentimento de pertencimento, a ampliação das relações humanas, possibilitando a interação entre pessoas que habitam o mesmo ambiente, mas devido a barreiras sociais não se comunicam, mesmo tendo interesses semelhantes - foram importantes motivadores. Estes motivadores possibilitaram o desenvolvimento de um trabalho realmente colaborativo para concretizar o evento, desde a idealização do evento até a preparação e operação do evento. As pessoas colocaram as suas habilidades à disposição para realizar o evento, habilidades manuais e intelectuais, pessoais (atividades que exercem como hobbies) e profissionais.

\subsection{Participantes}

O alcance regional do evento foi significativo, tendo como referência a cidade do Rio de Janeiro, pois houve inscrições de alunos de todas as universidades públicas sediadas na cidade, de algumas instituições de ensino privadas, pessoas vinculadas a empresas e cidadãos interessados no tema. As motivações apresentadas por estes indivíduos foram bem diversificadas, abrangendo, principalmente as seguintes questões: i) Objetivos pessoais: alguns inscritos buscavam parceiros para os seus projetos, que tinham relação com o tema do evento (Vivência Universitária), alguns indivíduos estavam motivados pela competição, pela oportunidade de mostrar as suas habilidades, ampliar o seu conhecimento e as suas relações profissionais (networking) e pessoais, aprender e vivenciar novas experiências; e ii) Voluntarismo cívico: a oportunidade de criar soluções que podem trazer benefícios para a sociedade, mais especificamente para resolver problemas vivenciados nas universidades, nas instituições públicas, na UNIRIO, foram motivações apresentadas. Alguns alunos que participaram do evento estudam ou estudaram em universidades onde é habitual a participação dos alunos em maratonas de programação ou Hackathons.

Outra questão relacionada à não participação da comunidade universitária da UNIRIO, é a crença de que somente os especialistas em TIC detém o conhecimento necessário para construir tais tecnologias, que os não tecnólogos não podem contribuir neste processo. As crenças de falta de habilidades, de que as ideias não serão implementadas, de que as soluções não terão nenhum efeito na instituição, se constituem como fatores de barreiras motivacionais (FERREIRA, 2017 apud WIJNHOVEN et al., 2015). Em um levantamento de opinião com 308 participantes de Hackathons no setor público, os resultados demonstraram que aprendizado, recompensas financeiras e divertimento influenciam a atitude relativa à participação em Hackathons, sendo que o divertimento é o maior influenciador (FERREIRA, 2017).

Diagnosticou-se que a comunidade universitária da UNIRIO ficou sensibilizada com o evento, pois houve expressivo apoio dos diversos atores de todas as suas classes funcionais e da administração da universidade, durante o Espaço de Ideias, diversas falas foram elogiosas aos objetivos do evento, que buscava soluções tecnológicas para a universidade. No entanto, como a jornada do Hack@UNIRIO incluía o desenvolvimento das soluções tecnológicas, não somente o seu design, acredita-se que os integrantes da UNIRIO não se consideraram capacitados para a implementação de tais tecnologias em um curto espaço de tempo. 


\subsection{Ambientes Virtuais de Participação Social}

O objetivo do Hack@UNIRIO era o desenvolvimento de protótipos de ambientes virtuais de participação social (AVPS) para evoluir (ampliar, facilitar, melhorar) a relação da comunidade universitária com a sua universidade, contexto chamado de Vivência Universitária, e a atuação desta comunidade no debate sobre soluções tecnológica que poderiam contribuir para amenizar os problemas vivenciados neste contexto. A expectativa era que o engajamento dos sujeitos imersos nos cenários-problema resultasse na proposição de soluções mais efetivas, que fossem voltadas para problemas reais, desejáveis pelos indivíduos e, com isso, fossem mais facilmente aceitas nesta comunidade, e desta forma pudessem impulsionar a transformação do cenário de participação social na UNIRIO.

Essa expectativa ainda não pode ser totalmente verificada, pois os AVPS ainda não foram disponibilizados para uso na universidade, mas as soluções propostas foram convergentes ao que foi debatido na Desconferência sobre Vivência Universitária, que possibilitou a imersão no tema. Pode-se afirmar que os AVPS concebidas no Hackathon estão focados em problemas reais, são centradas no usuário e promovem a colaboração. Todas as soluções propostas pelas equipes que participaram do evento podem ser caracterizadas como AVPS.

O desenho das soluções tecnológicas pode ter sido influenciado pela visão dos indivíduos que a propuseram, que eram, em sua maioria, alunos, com isso algumas soluções foram centradas nos problemas que os discentes vivenciam. No entanto, o evento contribuiu para mostrar o quão importante é a participação dos diversos atores para proposição de AVPS, pois, por exemplo, antes das pessoas se sentirem motivadas a reclamar sobre os serviços da universidade e propor formas de resolvê-los, a comunidade universitária quer saber o que está acontecendo na universidade, saber quais são as suas possibilidade e oportunidades.

\section{Conclusão}

Esta pesquisa-ação tinha como objetivo observar questões relacionadas à como desenvolver TICs para possibilitar a participação social no âmbito das instituições públicas com a contribuição da sociedade; quais seriam as características observadas dos sistemas desenvolvidos por meio desta atuação conjunta; e como se daria a motivação para atuar nestas atividades. A observação se deu no contexto de uma universidade pública, por meio de um evento de desenvolvimento aberto e colaborativo (Hackathon). A iniciativa de realização do Hack@UNIRIO propiciou algumas descobertas inesperadas, como os Hackathons se mostrarem como uma alternativa para a participação social.

Resultados. O Hackathon, que a princípio era considerado apenas um meio, se revelou como um instrumento complexo, com uma significativa agenda de pesquisa. Neste sentido, essa pesquisa contribuiu para o corpo de conhecimento sobre Hackathons realizados por instituições públicas, principalmente Instituições Federais de Ensino Superior (IFES), com o propósito de ampliar a participação social. A trajetória de realização do Hack@UNIRIO contribui para confirmar alguns aspectos críticos dos projetos de Hackathons promovidos por instituições públicas e fatores motivacionais dos indivíduos que participam de Hackathons, como objetivos pessoais e voluntarismo. 
Os aspectos motivacionais dos indivíduos para contribuir com a organização de Hackathons em IFES, atuando na sua idealização, planejamento e realização também é um contributo relevante. A ação realizada na UNIRIO por meio do Hack@UNIRIO produziu mudanças no cenário que foi aplicado, pois: possibilitou a proposição de soluções tecnológicas, que podem ser caracterizadas como AVPS; propiciou a interação (aproximação) entre diversos atores desta universidade e externo a esta, que discutiram abertamente sobre várias questões que afligem a comunidade universitária e novas relações sociais foram estabelecidas. A própria concretização do evento já é uma transformação no cenário de participação social da UNIRIO, pois demandou esforço de vários atores da instituição, que precisaram a atuar em regime de colaboração para que o evento fosse realizado, posicionando a universidade no cenário (circuito) de Hackathons.

O Hackathon se mostrou um instrumento de participação social, tanto em relação à organização colaborativa do evento, que propiciou que a equipe ampliasse o seu entendimento sobre os diversos contextos da UNIRIO e possibilitou a maior comunicação entre os seus diversos atores, que pode trazer inúmeros benefícios futuros. Em relação à realização do evento, o seu formato propiciou que os participantes conhecessem mais sobre o funcionamento da universidade, que possui processos, problemas, potencialidade, fragilidades, que são próprios desta instituição, mas alguns também são aplicáveis a outras instituições públicas de ensino.

Quanto aos efeitos do Hack@UNIRIO, já foram identificados alguns indícios da maior abertura (pré-disposição a cooperação da sociedade) da UNIRIO, pois o projeto Caronaê, um dos apoiadores do evento, será implantado na universidade por meio de um projeto de extensão, que pode ajudar a evoluir a interação social na universidade. No site institucional da UNIRIO foi disponibilizado mais um canal de informação, onde por meio de uma agenda online é possível acessar as informações sobre os eventos que estão ocorrendo na universidade.

O evento também contribuiu para revelar algumas questões que precisam avançar na universidade para que a participação social aconteça, como o Plano Institucional de Dados Abertos. A base de conhecimento apresentada neste trabalho também contribui para as organizações que desejam realizar Hackathons com o objetivo de propor soluções tecnológicas centradas em questões sociais, governamentais, de interesse público, ou seja, que visam promover alguma transformação social.

No âmbito das instituições públicas, esse trabalho contribui tanto para os aspectos de projeto (organização e realização) de Hackathons quanto para a promoção da participação social intra e extra organizacional. Em relação ao desenvolvimento de AVPS, esta pesquisa apresenta um método viável para a proposição deste tipo de sistema, que comporta as fases de ideação e prototipação dos AVPS, por meio de um modelo de desenvolvimento aberto e colaborativo. Neste modelo, as atividades são desenvolvidas com menor controle, sendo incentivada a colaboração, a transparência, 0 compartilhamento, o empoderamento de todos os envolvidos no projeto, enfim, lidando com os desafios do mundo aberto.

Contribuições. As principais contribuições desta pesquisa envolvem, primeiramente, reforçar a ideia de que a disponibilização de AVPS pelas instituições públicas pode contribuir para mudar o cenário de participação social no Brasil, de forma que - além de protestar, questionar os programas de governo, a agenda pública, as decisões que são tomadas pelos representantes políticos em nome do bem-estar social - a 
sociedade também possa contribuir para resolver os problemas, atuando em parceria com as instituições públicas, intervindo no ciclo de políticas públicas e serviços públicos, entre outras possibilidades. A realização de Hackathons pelas instituições públicas pode interferir positivamente nestes dois contextos, prover mais meios e "treinar" o cidadão, de forma que este possa usar a voz que lhe é concedida.

Acredita-se que é necessário ter ações mais abrangentes em relação à participação social, possibilitando que temas nacionais sejam discutidos, mas talvez a alavanca para que essas ações tenham maior engajamento sejam as iniciativas de micro participação social, desenvolvidas no âmbito das universidades, das instituições públicas e privadas, dentre outros atores sociais, como foi o Hack@UNIRIO.

A segunda contribuição da pesquisa é a descrição de uma trajetória de realização de Hackathons em universidades públicas para fins de participação social, incluindo etapas principais e estratégias de organização do evento. Outra contribuição desta pesquisa foi identificar que os ambientes virtuais de participação social produzidos de forma aberta e colaborativa tendem a apoiar situações ou resolver problemas vivenciados pelos próprios participantes, aumentando seu engajamento no desenvolvimento. Este aspecto foi reforçado pela adoção do Design Thinking e atividades de imersão durante o evento, o que aumentou a empatia dos participantes em relação aos problemas da universidade.

Por fim, esta pesquisa contribui na forma de demonstrar o potencial da pesquisaação para as pesquisas em Sistemas de Informação (SI), onde se deseja estudar o impacto e intervenção em contextos organizacionais e sociais.

Limitações e trabalhos futuros. $O$ ciclo de evolução e experimentação dos protótipos foi uma questão que não pôde ser explorada no âmbito desta pesquisa-ação. Este consiste na transformação dos protótipos em serviços e na disponibilização destes para uso, por exemplo, pela comunidade universitária. Algumas possibilidades que têm sido apresentadas é a incubação destas soluções tecnológicas, fruto da realização de Hackathons, em Laboratórios Hackers e Laboratórios de Inovação (FERREIRA, 2017). Este se constitui como um trabalho futuro a ser realizado, dar continuidade a projetos originários da participação social por meio de Hackathons.

Diversas questões relacionadas a esta iniciativa de participação social ainda podem ser exploradas ou aprofundadas, como o processo de transformação de ideias em serviços, aspectos relacionados à colaboração nas equipes que atuam em Hackathons, quais foram os benefícios da colocalização das equipes e questões relacionadas a sustentabilidade das soluções desenvolvidas nestes eventos. Estas pesquisas podem ocorrer por meio da proposição de novos ciclos de pesquisa-ação, estudos de caso ou Design Science Research (DSR).

A investigação do Hackathon como um ecossistema de software, onde podem ser explorados os seus aspectos sociais, técnicos e de negócios, também é um trabalho que pode ser desenvolvido. Algumas fases de desenvolvimento de soluções inovadoras associadas à abordagem Design Thinking para identificar se a solução foi devidamente implantada e se resolve o problema identificado na etapa de imersão também são questões que podem ser exploradas.

\section{Agradecimentos}


Renata Araujo é apoiada pelo CNPq por meio de Bolsa de Produtividade em Desenvolvimento Tecnológico e Extensão Inovadora, processo no 305060/2016-3.

\section{Referências}

Araujo, R. M. e Taher, Y. (2014) "Refining IT Requirements for Government-Citizen Co-participation Support in Public Service Design and Delivery". In: Conference for E-Democracy and Open Government, Krems: DonauUniversität Krems, v. 1., pp. 6172, Krems, Austria.

Barros, S. A. R. e Sampaio, R. C. (2017) “A Confiança para a Manutenção de uma Inovação Democrática: O caso do Orçamento Participativo Digital de Belo Horizonte".In: Cadernos Gestão Pública e Cidadania, v. 22, n. 72.

Braga, L. V. e Gomes, R. C. (2016) "Participação eletrônica e suas relações com governo eletrônico, efetividade governamental e accountability", Organizações \& Sociedade v. 23, n. 78 .

Brisoce, G. e Mulligan, C. (2014) "Digital Innovation: The Hackathon Phenomenon". Creativeworks London, (6), 1-13.

Caetano, B. P., Oliveira, G. W., Paula, M. M. e Souza, J. M. (2016) "Democracia digital: uma análise sobre recursos e aceitação". In: XII Simpósio Brasileiro de Sistemas de Informação (SBSI), pp. 128-135, Florianópolis, SC, Brasil.

CGI.BR (2014) “TIC Governo Eletrônico 2013: pesquisa sobre o uso das tecnologias de informação e comunicação no setor público brasileiro". Comitê Gestor da Internet no Brasil,http://www.cgi.br/media/docs/publicacoes/2/TIC_eGOV_2013_LIVRO_ELE TRONICO.pdf

CGI.BR (2016) "TIC Governo Eletrônico 2015: pesquisa sobre o uso das tecnologias de informação e comunicação no setor público brasileiro". Comitê Gestor da Internet no Brasil,http://www.cgi.br/media/docs/publicacoes/2/TIC_eGOV_2015_LIVRO_ELE TRONICO.pdf

CGI.BR (2018) “TIC Governo Eletrônico 2017: pesquisa sobre o uso das tecnologias de informação e comunicação no setor público brasileiro". Comitê Gestor da Internet no Brasil,https://cgi.br/media/docs/publicacoes/2/TIC_eGOV_2017_livro_eletronico.pd $\mathrm{f}$

Classe, T., Silva, J., Pimental, M., Araujo, R. M. (2016) "Uma Experiência de uso da Gamificação em Plataformas de Participação Social”, Revista Brasileira de Sistemas de Informação (iSys) v. 9, n. 1, p. 58-80, Edição Especial Governo Eletrônico.

Curtinovi, J. (2015) "GOVERNO ELETRÔNICO E DEMOCRACIA DIGITAL: mapeamento do uso da internet por órgãos públicos brasileiros a partir dos anos 2000". Revista Democracia Digital e Governo Eletrônico v. 1, n. 12, p. 120-149.

EGTI (2016) Estratégia de Governança Digital da Administração Pública Federal para o quadriênio 2016-2019. https://www .governodigital.gov.br/EGD/historico-1

Evans, M., Ferrarezi, E., Oliveira, C. G. e Grau, N. C. (2013) Participação social: textos para Discussão. Inovação para a Gestão Pública. Cooperação Brasil-Espanha. Ministério do Planejamento, Orçamento e Gestão. Caderno, v. 6. 
Faria, C. F. S. (2015) "Os Desafios do Estado Aberto: Facilitar a Visão do Cidadão e Dar Poder à sua Voz". In: Pesquisa sobre o uso das tecnologias da informação e comunicação no setor público: TIC Governo Eletrônico 2015. Comitê Gestor da Internet no Brasil, pp. 91-99. http://www.cgi.br.

FILIPPO, D., "Pesquisa-ação em sistemas colaborativos". In: Pimentel, M., Fuks, H. (eds). Sistemas Colaborativos, 1 ed., capítulo 26, Rio de Janeiro, RJ, Brasil, Elsevier, 2011.

Ferreira, G., D., "O papel dos Hackathons promovidos no setor público brasileiro: um estudo na perspectiva de inovação aberta, citizen-sourcing e motivação dos participantes". Dissertação de M.Sc., Faculdade de Economia, Administração, Contabilidade e Gestão de Políticas Públicas/UnB, Brasília, DF, Brasil, 2017.

Finocchio Junior (2013) Project Model Canvas: gerenciamento de projetos sem burocracia. São Paulo, Campus.

Freire, F. R. e Stabile, M. (2015) “As Novas Tecnologias e a Participação Eletrônica: Entre Promessas e Desafios”. In: Pesquisa sobre o uso das tecnologias da informação e comunicação no setor público: TIC Governo Eletrônico 2013. Comitê Gestor da Internet no Brasil, 2013. p. 47-56. http://www.cgi.br.

Herr, Kathryn; ANDERSON, Gary L. The action research dissertation: A guide for students and faculty. Sage publications, 2 ed., 2014.

Janowski, T. (2015) "Digital government evolution: From transformation to contextualization”, Government Information Quarterly v. 32, n. 3, pp. 221-236.

Johnson, P. e Robinson, P. (2014) "Civic Hackathons: Innovation, procurement, or civic engagement?", Review of Policy Research v. 31, n. 4, pp. 349-357.

LAI (2011) - Lei de Acesso à Informação (Lei $\mathrm{n}^{\mathrm{o}}$ 12.527/2011) http://www.planalto.gov.br/ccivil_03/_ato2011-2014/2011/lei/112527.htm

Lopes, K. M. G., Macadar, M., A. e Luciano, E. M. (2018) "Valor Público: O Cidadão no Centro da Gestão Pública". In: Pesquisa sobre o uso das tecnologias da informação e comunicação no setor público: TIC Governo Eletrônico 2017. Comitê Gestor da Internet no Brasil, pp. 75-83. http://www.cgi.br.

Macintosh, A. (2004) "Characterizing e-participation in policy-making”. System Sciences. Proceedings of the 37th Annual Hawaii International Conference on. IEEE, pp. 10.

Magdaleno, A. M. e Araujo, R. M. (2015) "Ecossistemas Digitais para o Apoio a Sistemas de Governo Abertos e Colaborativos". In: XI Simpósio Brasileiro de Sistemas de Informação (SBSI), v. 1, pp. 655-658, Goiânia, GO, Brasil.

Meireles, A. V. (2015) Democracia 3.0: interação entre governo e cidadãos mediada por tecnologias digitais. Dissertação de M.Sc., Instituto de Artes/UnB, Brasília, DF.

OGP Parceria para Governo Aberto https://www.opengovpartnership.org/

Panopoulou, E., Tambouris, E e Tarabanis (2014) K. "Success factors in designing eParticipation initiatives", Information and Organization v. 24, n. 4, p. 195-213. 
PDA (2016) Política de Dados Abertos do Poder Executivo Federal (Decreto $\mathrm{n}^{\circ}$ $8.777 / 2016)$ http://www.planalto.gov.br/ccivil_03/_Ato20152018/2016/Decreto/D8777.htm

Pinheiro, T., Alt, L. e Pontes, F. (2011) Design Thinking Brasil: empatia, colaboração e experimentação para pessoas, negócios e sociedade. São Paulo, Elsevier.

PNPS (2014) - Política Nacional de Participação Social (PNPS, Decreto ${ }^{\circ} 8.243 / 2014$ ) http://www.planalto.gov.br/ccivil_03/_Ato2011-2014/2014/Decreto/D8243.htm

Przeybilovicz, E., Cunha, M. A. A. e Coelho, T. R. (2015) "O Desenvolvimento dos Estudos sobre Governo Eletrônico no Brasil: Um Estudo Bibliométrico e Sociométrico". Revista Eletrônica de Sistemas de Informação, v. 14, n. 3.

Silva, J., Araujo, R. M. (2015) "Metodologias para o Desenvolvimento de Sistemas para Participação Eletrônica: Mapeamento Sistemático", RelaTe-DIA v. 8, n. 1.

Silva, J. "Uma Experiência de Desenvolvimento Aberto e Colaborativo de Ambientes Virtuais de Participação Social na UNIRIO”. Dissertação de M.Sc., Departamento de Informática Aplicada/UNIRIO, 2017.

RESUMO SÆBØ, Ø., Rose, J. e Flak, L. S. (2007) "The shape of eParticipation: Characterizing an emerging research area", Government Information Quarterly v. 25, n. 3, p. 400-428.

Steibel, F. (2015) Mecanismo independente de avaliação (IRM): Brasil-Relatório de Progresso 2013-2014. https://www.opengovpartnership.org/sites/default/files/Brasil_Relat\%C3\%B3rio2013 -14_Final_0.pdf

Susha, I. e Grönlund, ̊. (2012) "eParticipation research: Systematizing the field". Government Information Quarterly v. 29, n. 3, p. 373-382.

Vianna, M. J, S., Filho, Y. V. S, Adlerr, I. K., Lucena, B. F. e Russo, B. (2012) Design Thinking: Inovação em Negócios. Rio de Janeiro. MJV Press.

Vieira, G. S. (2016) "Governo eletrônico brasileiro: ações de integração entre sistemas de governo e sociedade”, Multi-Science Journal v. 1, n. 4, p. 24-33. 